HOSPITAL DE REABILITAÇÃO DE ANOMALIAS CRANIOFACIAIS

DANIEL LUIS PIRES ROSA

Avaliação da microestética dentária pós tratamento ortodôntico em pacientes com fissura transforame incisivo unilateral ou bilateral utilizando modelos digitais 



\section{Avaliação da microestética dentária pós tratamento ortodôntico em pacientes com fissura transforame incisivo unilateral ou bilateral utilizando modelos digitais}

Dissertação apresentada ao Hospital de Reabilitação de Anomalias Craniofaciais da Universidade de São Paulo para obtenção do título de Mestre em Ciências da Reabilitação.

Área de concentração: Fissuras Orofaciais e Anomalias Relacionadas Orientadora: Profa. Dra. Ana Lucia Pompéia Fraga de Almeida Coorientadora: Profa. Dra. Daniela Gamba Garib Carreira 


\section{UNIVERSIDADE DE SÃO PAULO \\ HOSPITAL DE REABILITAÇÃO DE ANOMALIAS CRANIOFACIAIS}

R. Silvio Marchione, 3-20

Caixa Postal: 1501

17012-900 - Bauru - SP - Brasil

Telefone: (14) 3235-8000

Prof. Dr. Marco Antônio Zago - Reitor da USP

Dra. Maria Aparecida de Andrade Moreira Machado - Superintendente do HRAC /USP

Autorizo, exclusivamente, para fins acadêmicos e científicos, a

reprodução total ou parcial desta Dissertação.

Daniel Luis Pires Rosa

Bauru, de de

\section{Rosa, Daniel}

R71a Avaliação da microestética dentária pós tratamento ortodôntico em pacientes com fissura transforame incisivo unilateral ou bilateral utilizando modelos digitais/ Daniel Luis Pires Rosa. Bauru, 2018.

75 p.; il., figs, tabs; $29,7 \mathrm{~cm}$.

Dissertação de Mestrado. Área de Concentração: Fissuras Orofaciais e Anomalias Relacionadas - Hospital de Reabilitação de Anomalias Craniofaciais, Universidade de São Paulo.

Orientador: Profa. Dra. Ana Lucia Pompéia Fraga de Almeida e coorientadora: Profa. Dra. Daniela Gamba Garib Carreira

Descritores: 1 Fenda labial. 2 Fenda palatina. 3 Estética 4 Ortodontia. 5 Periodontia. 


\section{FOLHA DE APROVAÇÃO}

\section{Daniel Luis Pires Rosa}

Dissertação apresentada ao Hospital de Reabilitação de Anomalias Craniofaciais da Universidade de São Paulo para a obtenção do título de Mestre.

Área de Concentração: Fissuras Orofaciais e Anomalias Relacionadas

Aprovado em:

\section{Banca Examinadora}

Prof. Dr.

Instituição

Prof. Dr.

Instituição

Prof. Dr.

Instituição

Profa. Dra. Ana Lucia Pompéia Fraga de Almeida

Hospital de Reabilitação de Anomalias Craniofaciais (HRAC-USP) (Orientadora)

Prof.(a) Dr.(a) Ana Paula Fukushiro

Presidente da Comissão de Pós-Graduação do HRAC-USP

Data de depósito da dissertação junto à SPG: 



\section{Dedicatária}

Dedico este trabalho a minha amada esposa, Anie Poter Rosa, que com generosidade, caridade e amor me auxilia e incentiva, todos os dias, no meu progresso enquanto marido, profissional e principalmente enquanto ser humano.

"Numa vida, várias vidas eu vivi. A melhor delas? Vivo agora, só depois que te (re)conheci." (Daniel Pires) 



\section{Agradecimentas}

Agradeço primeiramente a Deus cuja lógica e justiça nos permite evoluir um pouco mais a cada dia, etapa e jornada. Agradeço também a todos os colegas e pacientes do Centrinho que de forma direta ou indireta contribuíram para o resultado do meu trabalho, dentre esses, de forma especial, deixo meu agradecimento a minha orientadora, Profa. Dra. Ana Lúcia Pompéia Fraga de Almeida, a minha Coorientadora, Profa. Dra. Daniela Gamba Garib Carreira e também aos amigos: Aura Sofia Caceres Manfio, Rodrigo Ogawa e Rafael Ferreira.

"Se enxerguei mais longe, foi porque me apoiei sobre os ombros de gigantes" (Isaac Newton) 

"Embora ninguém possa voltar atrás e fazer um novo começo, qualquer um pode começar agora e fazer um novo fim."

Chico Xavier 



\section{LISTA DE ILUSTRAÇÕES}

Figura 1 - Definição dos pontos de referência para o plano oclusal .......................22

Figura 2 - Plano vestibular auxiliar do elemento $11 \ldots \ldots \ldots \ldots \ldots \ldots \ldots \ldots \ldots \ldots \ldots \ldots \ldots . . .23$

Figura 3 - Plano oclusal auxiliar ao nível da margem gengival do incisivo

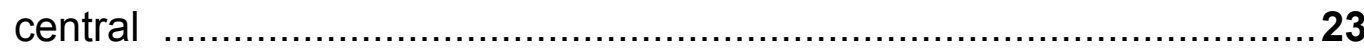

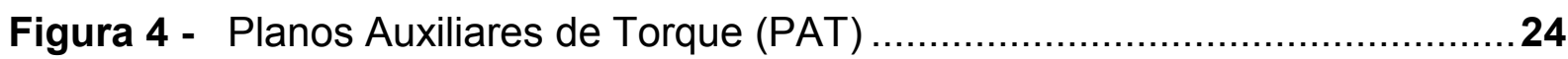

Figura 5 - Dimensionamento cervicoincisal e mesiodistal do elemento 11 ............25

Figura 6 - Proporção da largura aparente do lado esquerdo- 1:0,78:0,79 .............25

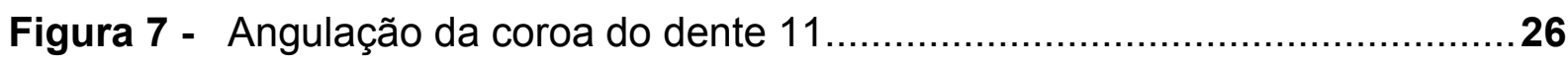

Figura 8 - Angulação do elemento 11 em relação ao plano oclusal .......................26

Figura 9 - Desnível entre as bordas incisais dos elementos 11, 12 e 13............27

Figura 10 - Desnível entre as margens gengivais .........................................28

Figura 11 - Corte Sagital do elemento 14 (substituto do 13) mostrando torque de $-1,7^{\circ}$

\section{LISTA DE TABELAS}

Tabela 1 - Descrição resumida dos membros pertencentes a cada grupo

Tabela 2 - Medidas correspondentes à proporção entre a largura e altura dentária do canino, incisivo lateral e central em cada grupo.

Tabela 3 - Medidas correspondentes à proporção da largura aparente do canino, incisivo lateral e central em cada grupo

Tabela 4 - Medidas correspondentes às distâncias verticais entre as bordas incisais em cada grupo.

Tabela 5 - Medidas correspondentes às distâncias verticais entre as margens gengivais do canino, incisivo lateral e central em cada grupo.

Tabela 6 - Medidas correspondentes à angulação do canino, incisivo lateral e central em cada grupo.

Tabela 7 - Medidas correspondentes à inclinação (torque) do canino, incisivo lateral e central em cada grupo. 



\section{LISTA DE ABREVIATURA E SIGLAS}

$<$

$>$

$\leq$

$\geq$

$\pm$

R

3D

A

ANG

$B$

CEP

D

d.p.

$\operatorname{Dr}(\mathrm{a})$.

DVB

DVM

$\mathrm{E}$

EOAS

et al.

$\mathrm{F}$

FOB

FB

FLP

FTI

FU

HRAC

JCE

IC

IL

INC

C

$\mathrm{M}$

$\mathrm{N}$

PLA

$\mathrm{PL} / \mathrm{H}$

PM

Prof(a).

POA

PVA

$\mathrm{Mm}$

RED

$\mathrm{S}$

SP

SF

USP
Porcentagem

Graus (angulação)

Menor

Maior

Menor ou igual

Maior ou igual

Desvio padrão

Marca registrada

Terceira dimensão

Ausente

Angulação da coroa dentária

Raça branca

Comitê de Ética em Pesquisa em Seres Humanos

Lado direito

Desvio padrão

Doutor(a)

Distância vertical entre as bordas incisais

Distância vertical entre as margens gengivais

Lado esquerdo

Enxerto ósseo alveolar secundário

E outros; Colaboradores

Gênero feminino

Faculdade de Odontologia de Bauru

Grupo fissura transforame incisivo bilateral

Fissura labiopalatina

Fissura transforame incisivo

Grupo fissura transforame incisivo unilateral

Hospital de Reabilitação de Anomalias Craniofaciais

Junção cemento-esmalte

Incisivo central

Incisivo lateral

Inclinação da coroa dentária -torque,

Canino

Gênero masculino

Raça negra

Proporção entre largura aparente em vista frontal

Proporção entre largura e altura dentária

Pré-molar

Professor(a)

Plano oclusal auxiliar

Plano vestibular auxiliar

Milímetros

Proporção dental estética recorrente

Sim/presente

São Paulo

Grupo sem fissura labiopalatina

Universidade de São Paulo 



\section{RESUMO}

Introdução: O objetivo dessa pesquisa é avaliar, após a finalização ortodôntica de adultos jovens reabilitados no Hospital de Anomalias Craniofaciais da Universidade de São Paulo (HRAC-USP),os aspectos microestéticos dos dentes anterossuperiores de indivíduos com fissura transforame incisivo (FTI) bilateral (FB) comparando-os com pacientes com FTI unilateral, considerando, desses últimos, os lados com fissura (FU) e sem fissura (SF). Assim, o incisivo central (IC), incisivo lateral (IL) e o canino (C) foram avaliados quanto à proporção entre largura e altura dentária $(\mathrm{PL} / \mathrm{H})$, proporção entre largura aparente em vista frontal -proporção áurea (PLA), distância vertical entre as bordas incisais (DVB), distância vertical entre as margens gengivais (DVM), angulação da coroa dentária (ANG) e inclinação da coroa dentária - torque (INC). Métodos: Foram estudados 100 modelos 3D obtidos por digitalização dos modelos de gesso de indivíduos com FTI (SF e FU: 59 pacientes e FB: 41 pacientes), os quais foram submetidos a análises no software OrthoAnalyzerTM 3D (3Shape A/S, Copenhagen, Denmark). As comparações entre os múltiplos grupos foram realizadas por meio do teste Kruskall-Wallis complementado pelo método de Dunn's nos dados não paramétricos, e teste Anova complementado com o teste Tukey nos dados paramétricos, adotando-se $5 \%$ como nível de significância. Resultados: A composição amostral em relação à idade (FU e SF: 21 anos; FB: 24 anos), gênero (FU e SF: 63\% homens e 37\% mulheres; FB: $68 \%$ homens e $32 \%$ mulheres) e raça, (FU e SF: $98 \%$ brancos e $2 \%$ negros; FB: $95 \%$ brancos e $5 \%$ negros) apresentou grande homogeneidade. No presente trabalho, somente a variável angulação não apresentou diferença entre grupos $(p>0,05)$. Para todas as outras houve diferença $(p<0,05)$ para pelo menos um dente $(C, I L, I C)$. Assim, a respeito da PL/H: em $C$ e IC, observou-se diferença $(p<0,05)$ entre FU e SF. Na PLA: para C/IL, ocorreu diferença $(p<0,05)$ entre SF com FU e FB e, para IL/IC, contatou-se diferença $(p<0,05)$ entre FU e SF. No que se refere à DVB: entre IC e $C$ houve diferença $(p<0,05)$ entre SF com FU e FB. Quanto à DVM: para $C$, a DVM mostrou-se diferente $(p<0,05)$ entre todos os grupos, e nos IL houve diferença $(p<0,05)$ entre SF com FB e FU; além disso, a DVM entre IC apresentou diferença $(p<0,05)$ entre indivíduos com FTI unilateral (SF+FU) comparados com FB. 

Na variável INC: para IL e IC, constatou-se diferença $(p<0,05)$ entre FU e FB. Conclusões: Dos resultados concluiu-se que há diferenças nos aspectos microestéticos dentários da região com fissura (FU e/ou FB) quando comparada a sem fissura (SF), havendo diferenças inclusive entre FU e FB. Notadamente, na $\mathrm{PL} / \mathrm{H}$ : há maiores proporções para $\mathrm{C}$ e menores para IC em FU que em SF. Quanto à PLA: entre C/IL encontrou-se valores maiores em SF que em FU e FB, e entre IL/IC, a PLA do grupo FU foi maior que a do SF. Relativo à DVB: constatou-se C mais proeminentes em SF que em FU e FB. Correspondente à DVM: tomando IC como referência, as DVM dos C são mais incisais na seguinte ordem: FU, FB e SF; para IL e a mesma referência, há menores DVM em FU e FB que em SF; e a DVM dos IC apresenta menores desníveis em FB que em SF+FU. Na INC: IL e IC apresentaram torques vestibulares menos acentuados em FB que em FU.

Palavras-chave: Fenda labial. Fenda palatina. Estética. Ortodontia. Periodontia. 



\section{ABSTRACT \\ Evaluation of dental micro-aesthetics after orthodontic treatment in patients with unilateral or bilateral complete cleft lip and palate using digital models}

Introduction: The aim of this study is to evaluate, after the orthodontic treatment of rehabilitated young adults at the Hospital of Craniofacial Anomalies of the University of São Paulo (HRAC-USP), the microesthetic aspects of the anteriorsuperior teeth in individuals with bilateral complete cleft $(F B)$ in comparison with unilateral complete cleft, considering, for the last ones, the sides with cleft (FU) and without cleft (SF). Thus, the central incisor (IC), the lateral incisor (IL) and the canine (C) were evaluated for the ratio between tooth width and height $(\mathrm{PL} / \mathrm{H})$, ratio between apparent width in frontal view (PLA), vertical distance between incisal edges (DVB), vertical distance between gingival margins (DVM), angulation of the dental crown (ANG) and inclination of the dental crown -torque (INC). Methods: For this, we studied one hundred 3D models obtained by scanning the plaster dental casts of individuals with complete clef lip and palate (SF and FU: 59 patients and FB: 41 patients), which were analyzed by OrthoAnalyzer 3D software (3Shape A / S, Copenhagen, Denmark). The comparisons between the multiple groups were performed through the Kruskall-Wallis test complemented by the Dunn's method in the non-parametric data, and the Anova test complemented with the Tukey test in the parametric data, adopting $5 \%$ as a level of significance. Results: The sample composition in relation to age (FU e SF: 21 years; FB: 24 years), gender (FU and SF: $63 \%$ men and $37 \%$ women, FB: $68 \%$ men and $32 \%$ women) and race(FU and SF: 98\% white and 2\% black; FB: $95 \%$ white and 5\% black), presented great homogeneity. In the present study, only the angulation variable presented no difference between groups $(p>0.05)$. For all others there was difference $(p<0.05)$ for at least one tooth $(\mathrm{C}, \mathrm{IL}, \mathrm{Cl})$. Thus, regarding $\mathrm{PL} / \mathrm{H}$ : in $\mathrm{C}$ and $\mathrm{IC}$, a difference $(\mathrm{p}$ $<0.05$ ) was observed between FU and SF. In the PLA: for C / IL, there was a difference $(p<0.05)$ between SF with FU and FB and, for the IL / IC, a difference ( $p$ $<0.05$ ) between FU and SF was reported. Concerning DVB: between IC and C there 

was difference $(p<0.05)$ between SF with FU and FB. As for DVM: for C, the DVM was different $(p<0.05)$ between all the groups, and in the IL there was a difference $(p$ $<0.05$ ) between SF with FB and FU; in addition, DVM between IC presented a difference $(p<0.05)$ for individuals with complete unilateral cleft $(S F+F U)$ compared to FB. In the variable INC: for IL and IC, a difference $(p<0.05)$ between FU and FB was found. Conclusions: From the results, it was concluded that there are differences in the dental microaesthetic aspects of the cleft area (FU and / or FB) when compared to area without cleft (SF). There are even differences between FU and FB. Notably: In PL / H: there are larger proportions for $\mathrm{C}$ and smaller for IC in FU than in SF. As for PLA: between C / IL higher values were found in SF than in FU and FB, and between IL / IC, the PLA of FU group was higher than SF. Relative to DVB: $C$ were more prominents in SF than in FU and FB Corresponding to DVM: taking IC as reference, the DVM of $C$ are more incisal in the following order: FU, FB and SF; for IL and the same reference, there are smaller DVM in FU and FB than in SF; and the DVM of the IC shows smaller differences in FB than in SF + FU. In INC: $\mathrm{IL}$ and IC had less marked vestibular torques in FB than in FU.

Keywords: Cleft Lip. Cleft Palate. Esthetics. Orthodontics. Periodontics. 



\section{SUMÁRIO}

1 INTRODUÇÃO

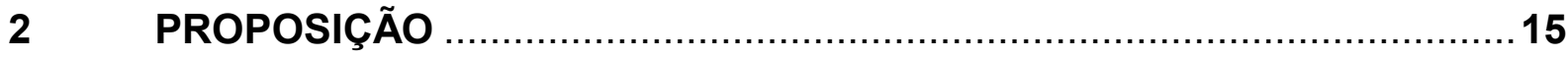

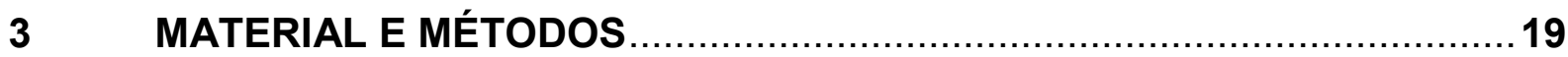

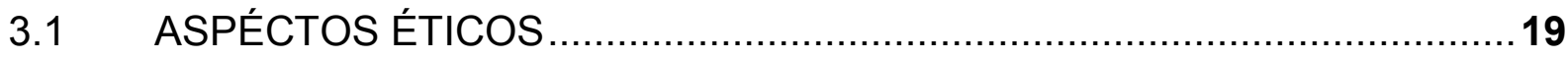

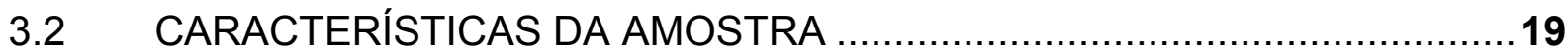

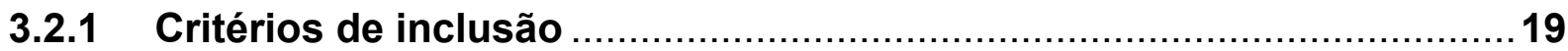

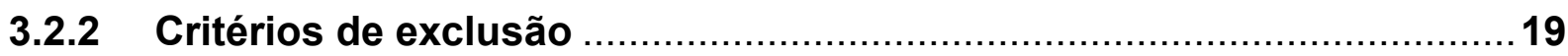

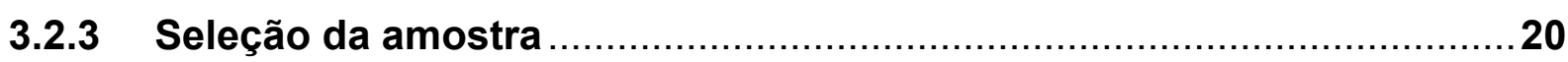

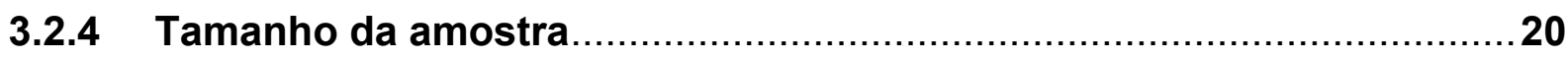

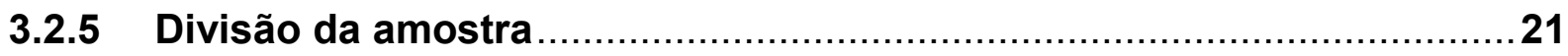

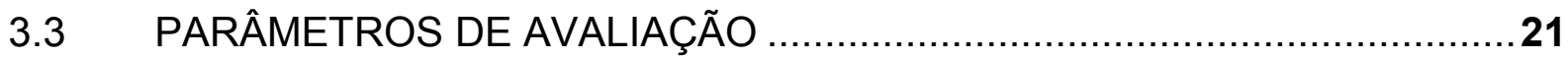

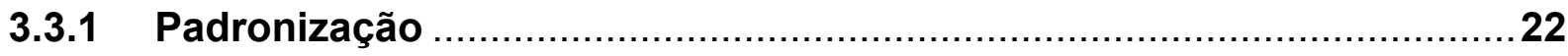

3.3.2 Definição do plano oclusal e a posição do modelo ………....................22

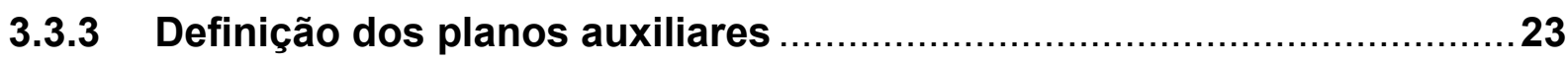

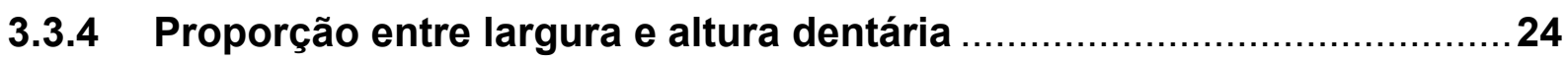

3.3.5 Proporção da largura aparente em vista frontal (proporção áurea).......25

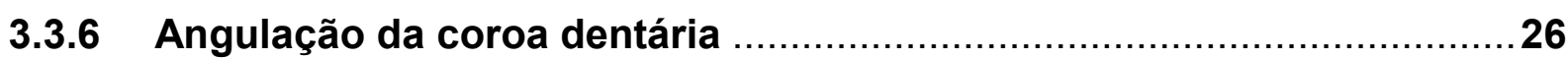

3.3.7 Distância vertical entre as bordas incisais ......................................27

3.3.8 Distância vertical entre as margens gengivais ................................. 27

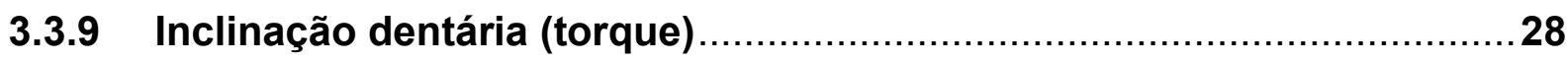

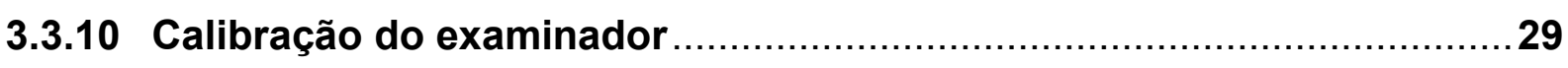

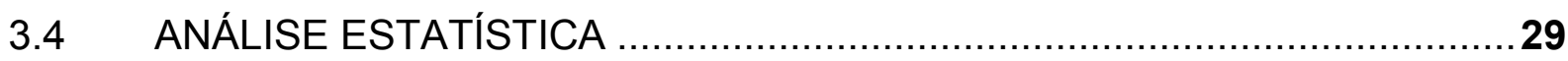

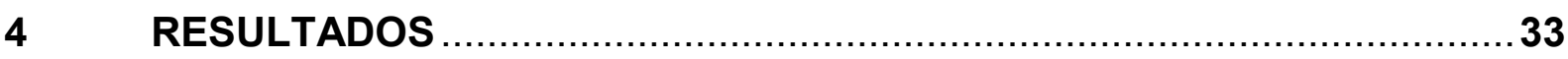

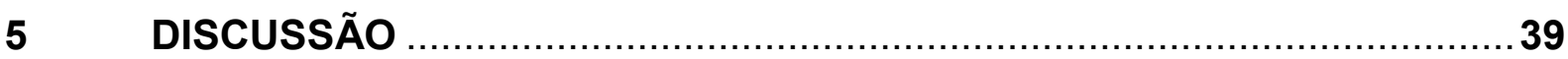

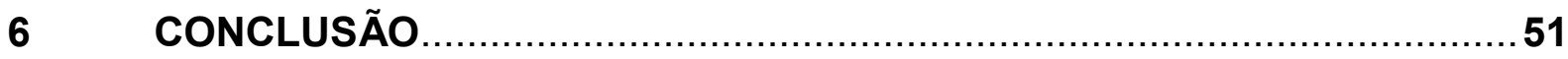

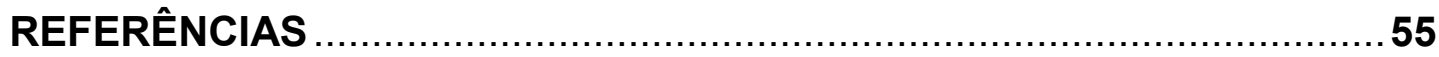

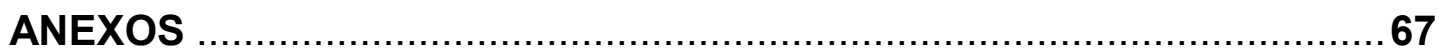



Intraduçãa 



\section{INTRODUÇÃO}

As fissuras labiopalatinas (FLP) são as mais frequentes malformações craniofaciais em humanos. (BAGHERI; JO, 2013). No mundo, essa malformação acomete um a cada 700 nascidos vivos (DIXON et al., 2011). Trata-se de uma anomalia de ordem congênita que afeta, funcional e esteticamente, o complexo maxilofacial com características e severidades variadas (TRINDADE; SILVA FILHO, 2000; FREITAS et al., 2012).

Nesse contexto, do ponto de vista psicossocial, estudos mostram que a aparência facial influencia a capacidade de interação social, auto-satisfação e desenvolvimento psicológico.(THOMAS et al., 1997; LANGLOIS et al., 2000; VAN DER GELD, 2007; BULL; RUMSEY, 2012). Assim, conclui-se que a agradabilidade da face é fator que favorece o indivíduo socialmente e consequentemente resulta comportamentos mais positivos à indivíduos de face esteticamente harmônica (LANGLOIS et al.).

Sendo o primeiro contato visual quando interagimos socialmente, o sorriso tem sido objeto de estudo de diversos autores que reportam sua relevância como componente estético da face e também como ferramenta de comunicação e interação social, elementos que fazem dessa expressão uma das mais importantes da face (TJAN, MILLER, THE, 1984; PECK, PECK, KATAJA, 1992; DUNN, MURCHISON, BROOME, 1996; CALVO et al., 2013).

Portanto, parece claro que a reabilitação do complexo maxilofacial deve almejar não apenas objetivos funcionais, mas também estéticos, sobretudo nos indivíduos com FLP, uma vez que tanto a malformação congênita quanto as cicatrizes das cirurgias reparadoras são fatores que prejudicam a harmonia estética da face (TRINDADE; SILVA FILHO, 2000; FREITAS et al., 2012). Dessa forma, ao reabilitar o sorriso desses indivíduos favorece-se a estética da face e, por conseguinte, intenciona-se alcançar um desenvolvimento psicossocial mais saudável (THOMAS et al., 1997; LANGLOIS et al., 2000).

Do ponto de vista técnico, a análise da aparência facial pode ser dividida em três aspectos: macroestética, miniestética e microestética. A macroestética relaciona-se com a avaliação das proporções e harmonia da face nos três planos. A miniestética avalia a relação estética da exposição de dentes e periodonto. Por fim, 
a microestética propõe avaliar dentes e periodonto circunjacente no que se refere a suas proporções e relações (PROFIT, SARVER E ACKERMAN, 2007). Assim, tanto a miniestetica quanto a microestética avaliam estruturas bucais e suas relações para compreender o que torna um sorriso bonito.

Em pacientes com FLP, alguns estudos relacionados à miniestética tem buscado desvendar as características da agradabilidade do sorriso. Nesse aspecto, $84,4 \%$ avaliam-se com sorrisos esteticamente agradável, em média a curvatura de seus lábios superiores apresenta-se mais reta e, do ponto de vista da exposição de dentes e periodonto, seus sorrisos são considerados com altura mediana (ESPER et al 2009; ESPER et al 2012). Na avaliação da interdependência entre as características dos tecidos moles da área da fissura com o oral health-related quality of life (OHRQoL), observou-se melhores índices do OHRQoL quando a reabilitação da região com fissura era realizada por fechamento de espaços com dentes do próprio paciente, sem o auxilio de implantes ou próteses (STELZLE et al., 2017).

Com relação a microestética há diversos estudos em indivíduos sem fissura. Dessa maneira, pode-se considerar como sendo elementos da microestética dentária: a proporção entre largura e altura de um mesmo dente anterossuperior; a proporção da largura aparente em vista frontal dos dentes anterossuperiores entre si (proporção áurea), o desnível entre as margens gengivais, os degraus entre bordas incisais dos elementos anterossuperiores, a angulação e a inclinação dentária, (FRUSH; FISHER, 1958; HUSLEY, 1970; KOKICH et al., 1999; SARVER, 2001; PROFIT, SARVER E ACKERMAN, 2007; MACHADO, 2013).

No entanto, estudos voltados especificamente à análise da microestética de indivíduos com FLP não foram encontrados. Assim, o propósito desse estudo é analisar e descrever algumas características da microestética dentária de pacientes com FLP, buscando elucidar suas diferenças frente à região em que a fissura não esta presente. 
Prapasiçãa 



\section{PROPOSIÇÃO}

Objetivo primário:

- avaliar, após a reabilitação ortodôntica no Hospital de Anomalias Craniofaciais da Universidade de São Paulo (HRAC-USP), os aspectos microestéticos dos dentes anterossuperiores de adultos jovens com fissura transforame incisivo (FTI) bilateral (FB) comparando-os com pacientes com FTI unilateral, considerando, desses últimos, os lados com fissura (FU) e sem fissura (SF).

Objetivo secundário:

- avaliar a proporção correspondente entre a largura e altura do canino, incisivo lateral e central do arco superior em cada grupo;

- avaliar as medidas correspondentes à proporção da largura aparente em vista frontal do canino, incisivo lateral e central do arco superior em cada grupo;

- avaliar as medidas correspondentes às distâncias verticais entre bordas incisais do canino, incisivo lateral e central do arco superior em cada grupo;

- avaliar as medidas correspondentes às distâncias verticais entre margens gengivais do canino, incisivo lateral e central do arco superior em cada grupo;avaliar as medidas correspondentes à angulação do canino, incisivos lateral e central do arco superior em cada grupo.

- avaliar as medidas correspondentes à inclinação do canino, incisivo lateral e central do arco superior em cada grupo;

Hipótese nula:

- não há diferença nos aspectos microestéticos da aparência facial de adultos jovens com FTI unilateral (FU) ou com FTI bilateral (FB) em relação ao lado sem fissura (SF) após tratamento ortodôntico. 

Materiais e

métadas 



\section{3 - MATERIAIS E MÉTODOS}

\subsection{ASPECTOS ÉTICOS}

Anteriormente a execução desse trabalho, a proposta foi submetida à apreciação (CAAE: 62382916.2.0000.5441) pelo Comitê de Ética em Pesquisa com Seres Humanos do HRAC-USP, respeitando a Resolução 196/96, que versa sobre ética em pesquisas da Comissão Nacional de Ética em Pesquisa - CONEP (Anexo $3)$.

\subsection{CARACTERÍSTICAS DA AMOSTRA}

Com o objetivo de padronizar a seleção dos pacientes de maneira a obter uma amostra homogênea, foram utilizados os seguintes critérios:

\subsubsection{Critérios de inclusão}

Os critérios de inclusão para os participantes da pesquisa foram:

- Faixa etária: de 15 a 35 anos

- Ambos os gêneros

- Classificação da fissura: fissura transforame incisivo unilateral esquerda ou direita, como também pacientes com fissura transforame incisivo bilateral;

- Tratamento Reabilitador: submetidos às cirurgias primárias (queiloplastia e palatoplastia), enxerto ósseo alveolar secundário (EOAS) e tratamento ortodôntico finalizado nos anos de 2013 a 2017 no HRACUSP.

\subsubsection{Critérios de exclusão}

Já como critérios de exclusão, foram adotados:

- indivíduos com síndromes ou doenças sistêmicas com repercussão oral; 
- espaço edêntulo ou reabilitado com próteses sobre dentes ou implantes na região anterior superior.

- modelos digitais de qualidade incompatível com as análises propostas.

Embora cirurgia ortognática, e pequenos procedimentos de reanatomização da coroa clínica (por desgaste ou resina) possam influenciar as características microestéticas naturais, tais fatores não compuseram os critérios de exclusão. Isso porque a alta prevalência (Anexos 1 e 2) desses procedimentos indica o caráter de normalidade na sua adoção como procedimento auxiliar à finalização ortodôntica. De tal forma que, se critério de exclusão fosse, inviabilizaria o tamanho amostral adequado.

\subsubsection{Seleção da amostra}

Para a seleção da amostra foram avaliadas, segundo os critérios de inclusão e exclusão, todas as fichas de pacientes ortodonticamente finalizados no HRACUSP durante o período declarado. Tal avaliação processou-se segundo informações contidas no prontuário digital (TASY ${ }^{\circledR}$, Philips, São Paulo, Brasil) complementada pela análise das imagens e modelos digitais presentes no banco de dados do HRAC-USP.

\subsubsection{Tamanho da Amostra}

Para o cálculo amostral, utilizou-se o Software SigmaPlot for Windows versão 12.0 (Systat Software,San Jose, CA, USA), o qual, para o teste ANOVA (dados: minimum detectable difference in means $=0,5$; expected standard deviation os residuals $=1,1$; number of groups $=3$; desired power $=0,8$; alpha $=0,05)$, estimou serem necessários 93 indivíduos para compor a amostra. Contudo, a amostra utilizada (100 modelos digitais) corresponde à quantidade total de modelos presentes no banco de dados do HRAC-USP, conforme os critérios de inclusão e exclusão da pesquisa. 


\subsubsection{Divisão da amostra}

A amostra foi dividida em três grupos:

- Grupo com fissura transforme incisivo bilateral (FB): avaliados modelos dentários digitais do arco superior de pacientes que apresentam FTI bilateral;

- Grupo com fissura transforme incisivo unilateral (FU): avaliado o lado com fissura dos modelos dentários digitais do arco superior de pacientes que apresentam FTI unilateral;

- Grupo sem fissura (SF): avaliado o lado sem fissura (correspondente ao lado contralateral do grupo FU) dos modelos dentários digitais do arco superior de pacientes que apresentam FTI unilateral.

\subsection{PARÂMETROS DE AVALIAÇÃO}

No presente estudo, foram utilizados modelos 3D obtidos por escaneamento do modelo de gesso dos indivíduos componentes dos grupos. Para tanto, utilizou-se o scanner de modelos de gesso 3Shape R700 (3Shape A/S, Copenhagen, Denmark).

Uma vez digitalizados, os modelos foram analisados, por apenas um examinador, no ambiente virtual do software OrthoAnalyzerTM 3D (3Shape AVS, Copenhagen, Denmark). Foram analisados os elementos anterossuperiores, ou seja, os elementos que se encontravam nas posições dos incisivos centrais (IC), laterais (IL) e caninos (C) do arco superior (independente de serem ou não os referidos dentes), quanto aos seguintes aspectos:

- Proporção entre largura e altura dentária (PL/H);

- Proporção da largura aparente em vista frontal (PLA);

- Distância vertical entre as bordas incisais (DVB);

- Distância vertical entre as margens gengivais (DVM);

- Angulação da coroa dentária (ANG);

- Inclinação da coroa dentária - torque (INC). 


\subsubsection{Padronização}

Antes do início da tomada das medidas, cada modelo digitalizado teve sua posição padronizada, assim como alguns planos auxiliares foram constituídos. Tais procedimentos visaram aumentar a precisão e reprodutibilidade das mensurações tomadas, na tentativa de reduzir qualquer forma de viés.

\subsubsection{Definição do plano oclusal e a posição do modelo.}

Após importar o modelo para o ambiente virtual do software, com a ferramenta "setup occlusion plane" estabeleceu-se o plano oclusal com as seguintes referências: um ponto na cúspide mesiovestibular do elemento 16 , outro na cúspide mesiovestibular do elemento 26 (ambos na porção mais proeminente das respectivas cúspides) e, um último, na borda mesioincisal do elemento 21 ou 11 , aquele que possuísse a referida borda mais incisal e íntegra (Figura 1).

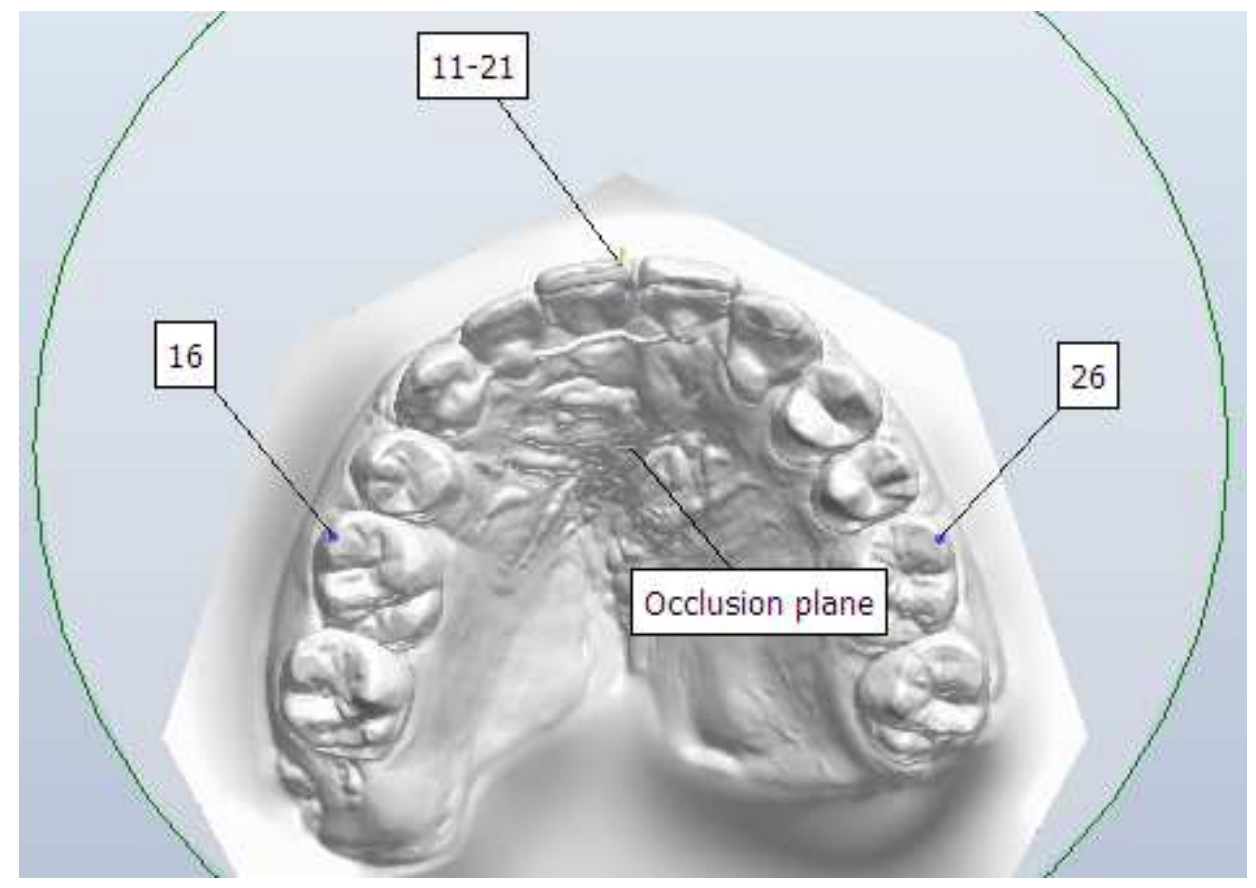

Figura 1: Definição dos pontos de referência para o plano oclusal.

Definido o plano oclusal, a posição de cada modelo foi alterada de forma que o plano oclusal ficasse paralelo ao plano transversal definido pelo software. 


\subsubsection{Definição dos planos auxiliares}

Com o auxílio da ferramenta "planes", marcaram-se três pontos de referência sobre a vestibular de cada um dos elementos anterossuperiores a serem avaliados. Depois, utilizando a ferramenta "Standard planes" criou-se uma tela quadriculada à frente da face vestibular do elemento dentário, a qual foi denominada como plano vestibular auxiliar (PVA). Dessa forma, objetivou-se o reconhecimento mais preciso dos pontos de referência que serão usados para fazer os dimensionamentos a seguir (Figura 2).

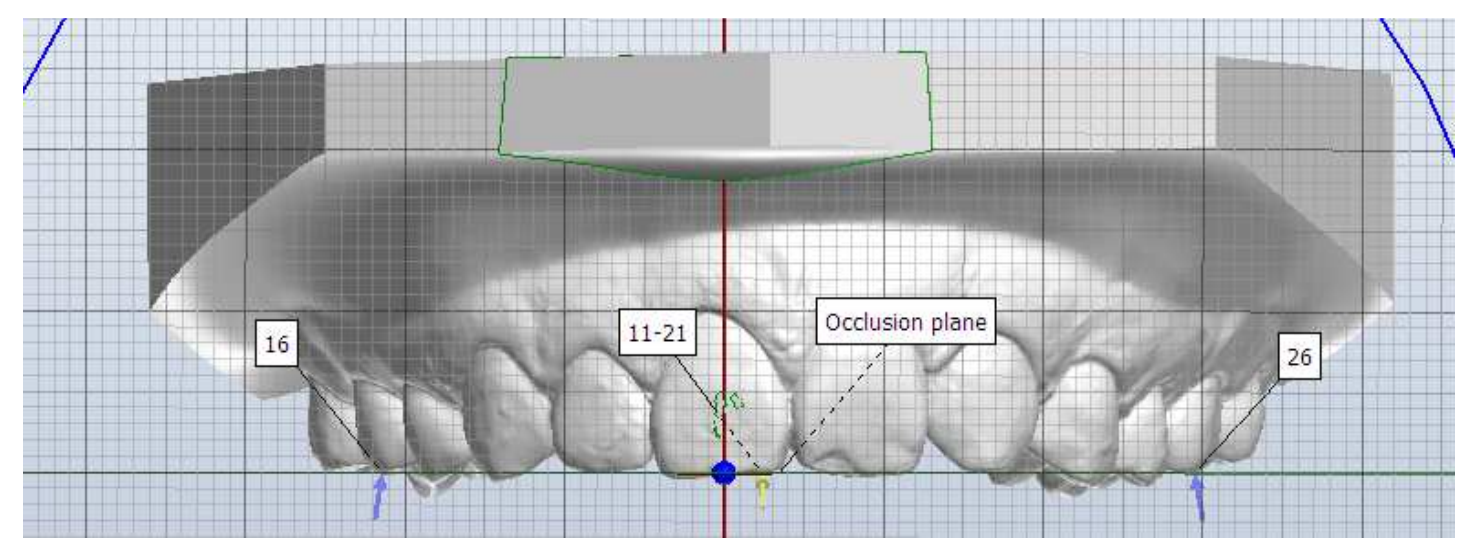

Figura 2: Plano vestibular auxiliar do elemento 11.

O segundo plano auxiliar, plano oclusal auxiliar (POA), foi construído similarmente ao anterior, definido paralelamente ao plano oclusal e posicionado ao nível da margem gengival do incisivo central cuja gengiva marginal estivesse mais apical (Figura 3).

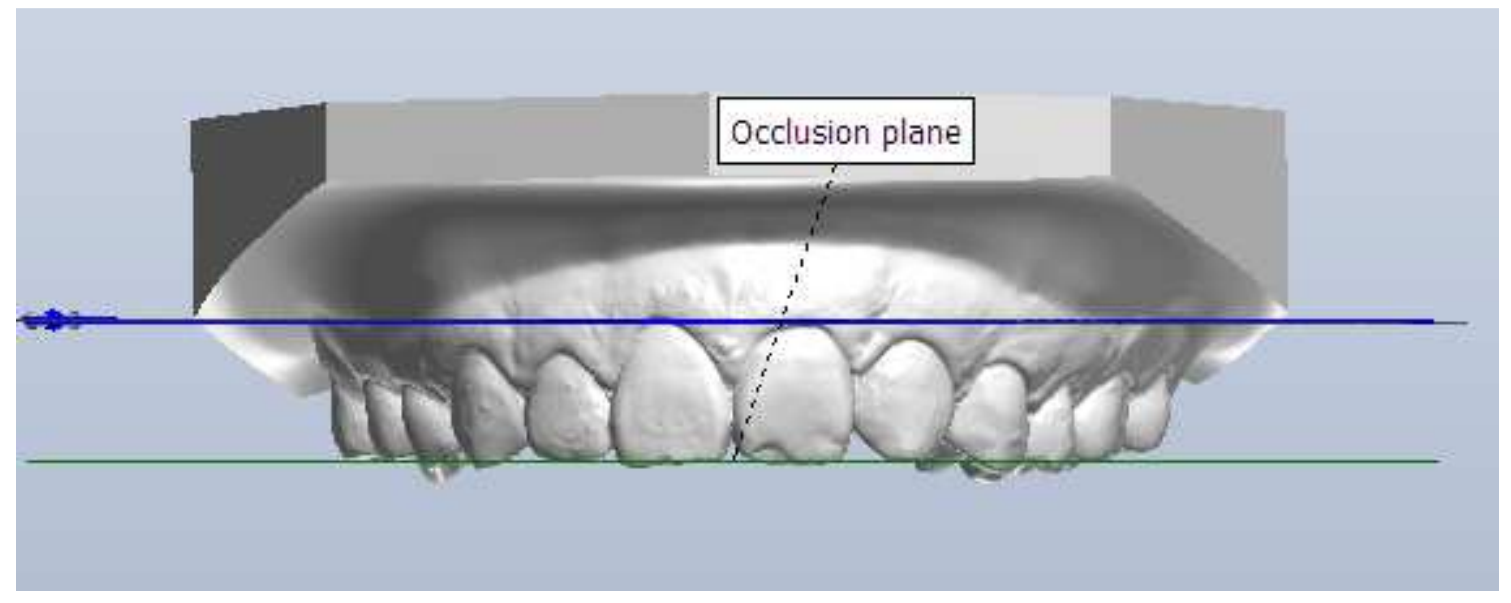

Figura 3: Plano oclusal auxiliar ao nível da margem gengival do incisivo central. 
Por fim, constituiu-se os planos auxiliares de torque (PAT), esses planos foram definidos de modo a dividir cada elemento analisado no sentido do seu longo eixo. Para tanto, em cada dente foi marcado com a ferramenta "planes" um ponto sobre a cervical palatina, o segundo sobre a incisal e o terceiro na cervical vestibular, todos no centro mesio-distal do dente (Figura 4).

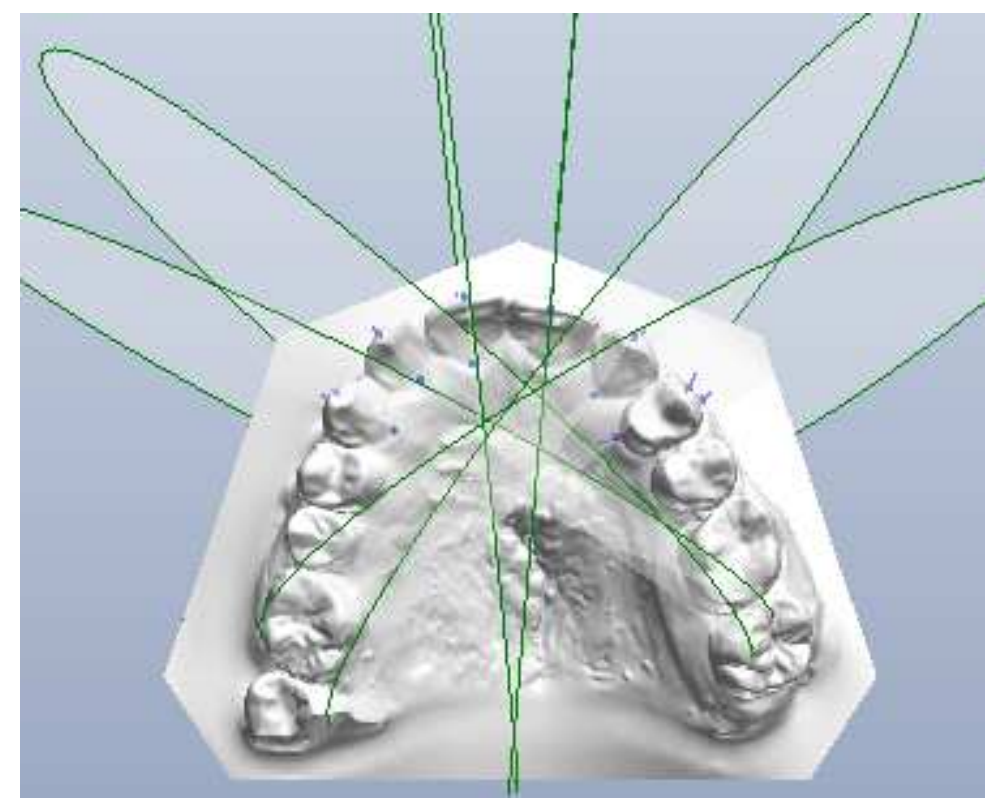

Figura 4: Planos Auxiliares de Torque (PAT)

\subsubsection{Proporção entre largura e altura dentária}

Procedimento de mensuração: primeiramente, manipulando a rotação do PVA, estabeleceu-se um paralelismo entre as linhas verticais deste com o longo eixo do dente. No próximo passo, com a ferramenta "Caliper", marcou-se um ponto na distal e outro na mesial de cada elemento, certificando-se (através da grade do PVA) de que estes pontos correspondiam a maior dimensão mesio-distal do respectivo dente. No concernente a medida da altura da coroa dentária, mediu-se a maior distância cervicoincisal do dente (Figura 5). Por fim, dividiu-se o valor da medida mesiodistal pela cervicoincisal, obtendo-se a proporção entre largura e altura do dente. 


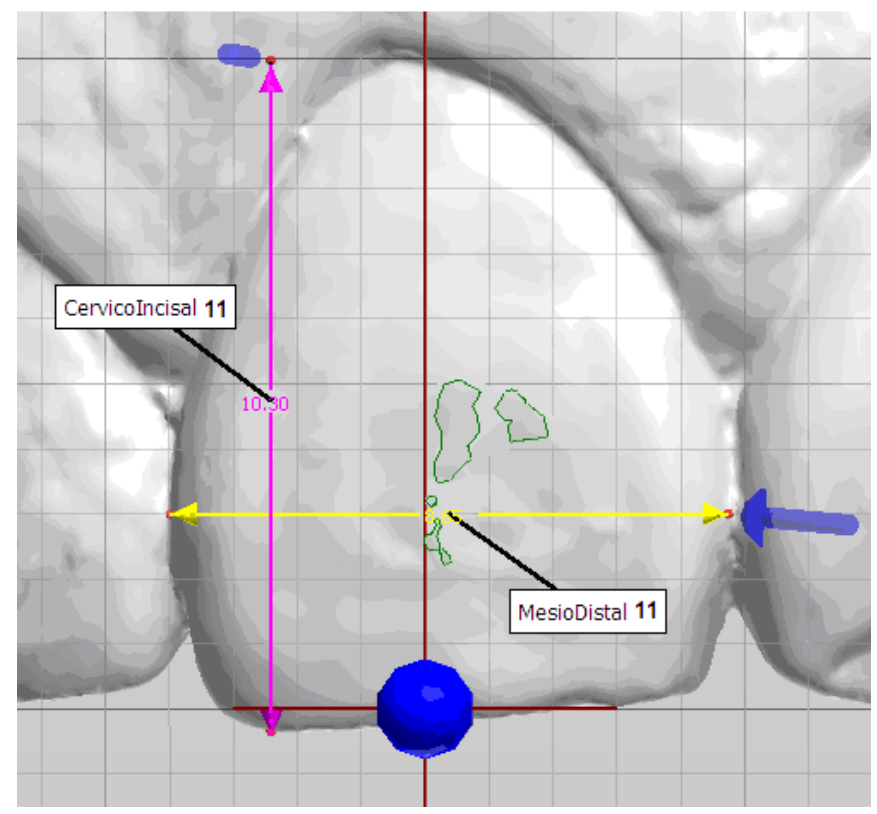

Figura 5: Dimensionamento cervicoincisal e mesiodistal do elemento 11.

\subsubsection{Proporção da largura aparente em vista frontal (proporção áurea)}

Procedimento de mensuração: utilizando-se a ferramenta "Caliper", mediu-se a distância mesiodistal aparente das coroas dos elementos dentários (Figura 6). 0 cálculo da proporção da largura aparente foi definido pela divisão da medida obtida do canino por aquela do incisivo lateral contíguo e da medida deste pela auferida do incisivo central ipsilateral.

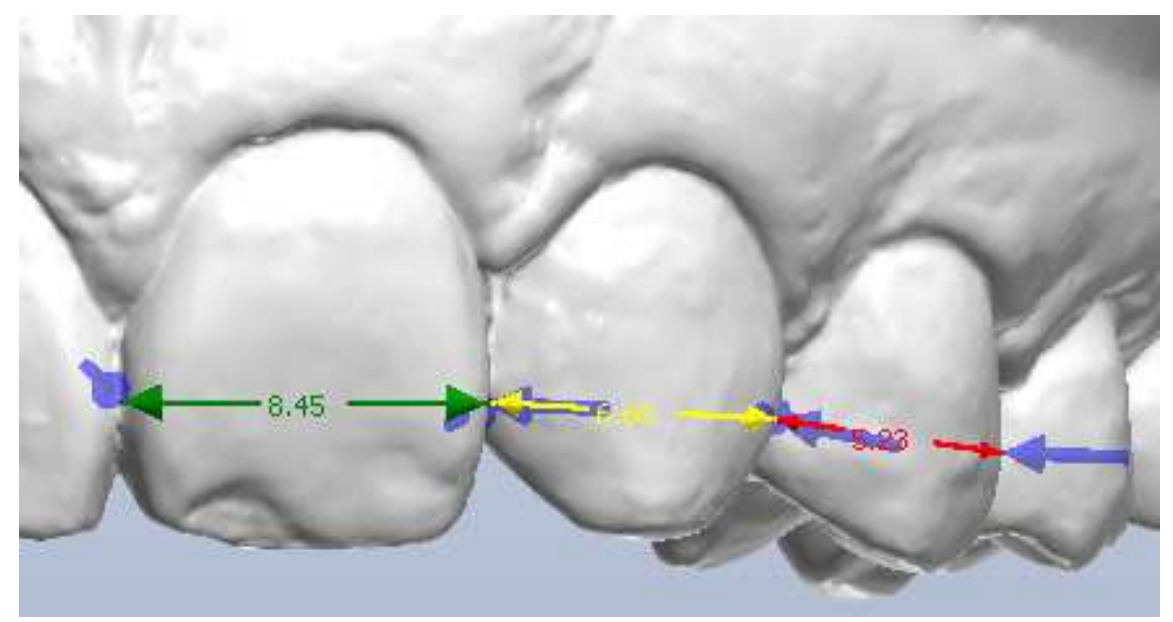

Figura 6: Proporção da largura aparente do lado esquerdo (1:0,78:0,79). 


\subsubsection{Angulação da coroa dentária}

Procedimento de mensuração: com a ferramenta "Angles", marcou-se os dois primeiros pontos sobre o longo eixo do dente, seguindo o PVA como referência. O terceiro ponto foi marcado paralelo ao plano oclusal. Finalmente, subtraiu-se 90 graus da medida apurada, de modo a obter-se a angulação da coroa dentária em relação ao plano longitudinal da arcada (Figuras 7 e 8), de forma semelhante à metodologia de Andrews (1972).

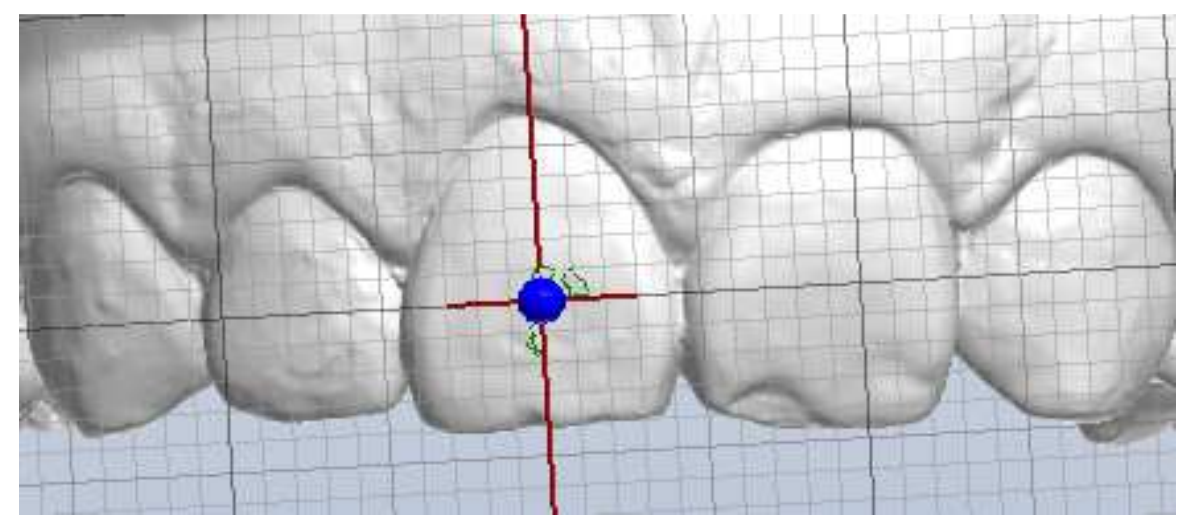

Figura 7: Angulação da coroa do dente 11.

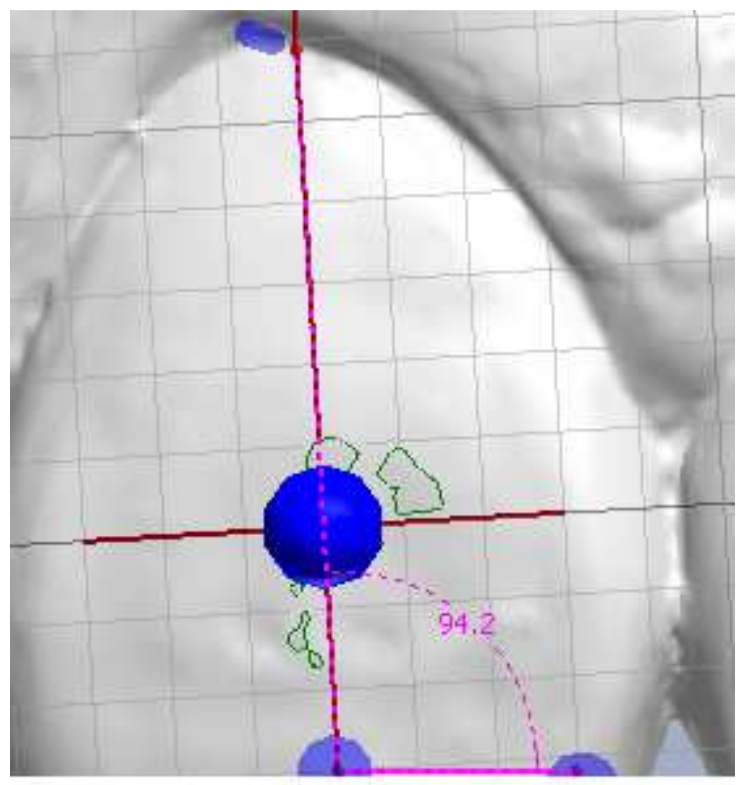

Figura 8: Angulação do elemento 11 em relação ao plano oclusal. 


\subsubsection{Distância vertical entre as bordas incisais}

Procedimento de mensuração: mediu-se, com a ferramenta "Caliper", a distância entre a porção mais incisal do elemento até o plano oclusal auxiliar (POA Figura 9). Para o cálculo do declive do IL e C, o elemento 11 foi tomado como referência para os elementos 12 e 13, assim como o dente 21 foi referência para os dentes 22 e 23. Já para o desnível entre incisivos centrais, adotou-se o IC do lado não fissurado como referência para os grupos FU e SF, enquanto para o grupo FB esse papel coube ao elemento 11. Por fim, subtraíram-se as medidas dos incisivos laterais e caninos daquela auferida para suas respectivas referências.

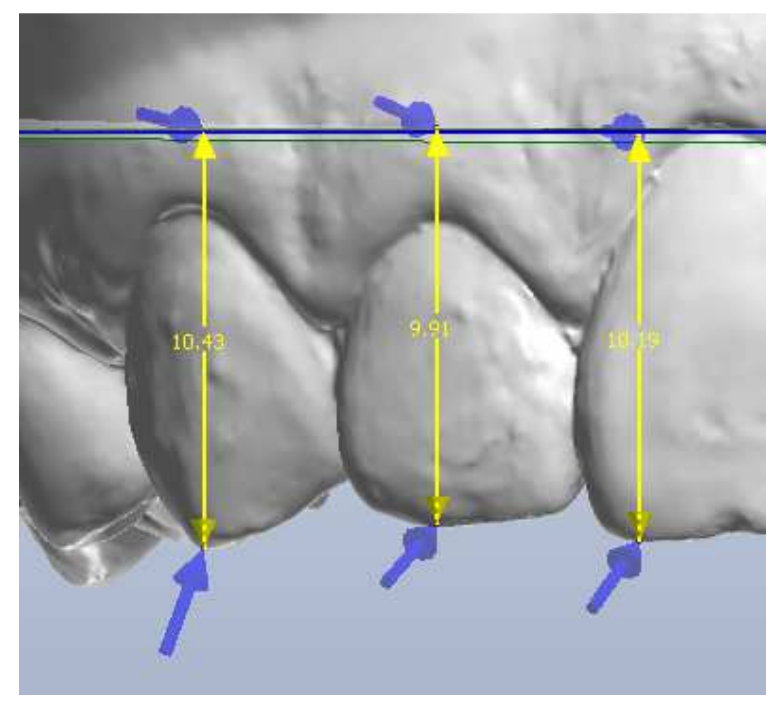

Figura 9: Desnível entre as bordas incisais dos elementos 11, 12 e 13.

\subsubsection{Distância vertical entre as margens gengivais}

Procedimento de mensuração: usando a ferramenta "Caliper", mediu-se a distância linear entre a margem gengival e o POA (Figura 10). Para o cálculo dos desníveis, manteve-se as mesmas referências e procedimentos adotados para a mensuração da distância vertical entre as bordas incisais. 


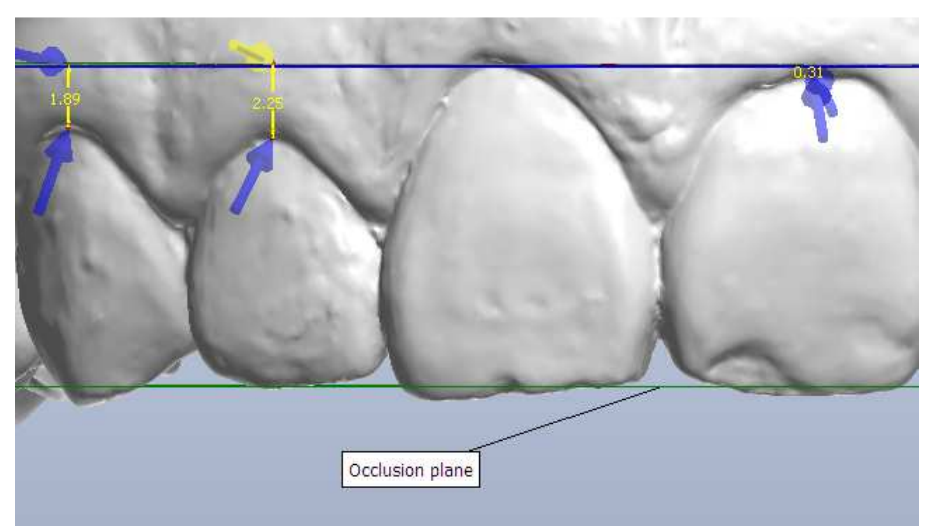

Figura 10: Desnível entre as margens gengivais.

\subsubsection{Inclinação dentária (torque)}

Procedimento de mensuração: em "Cross-section - Standard Planes" seleciona-se o PAT do dente a ser mensurado. Promove-se o corte do modelo sobre o plano sagital (Clipping plane) definido pelo PAT. Depois utilizando a ferramenta "Angle Measurement", mensura-se o torque da coroa. Isso se faz localizando os dois primeiros pontos sobre o contorno vestibular (no mesmo local onde se colaria o braquete ortodôntico) e o terceiro ponto é definido paralelo ao plano oclusal (Figura 11). Do valor obtido subtraiu-se $90^{\circ}$ de modo semelhante à metodologia adotada por Andrews (1972).

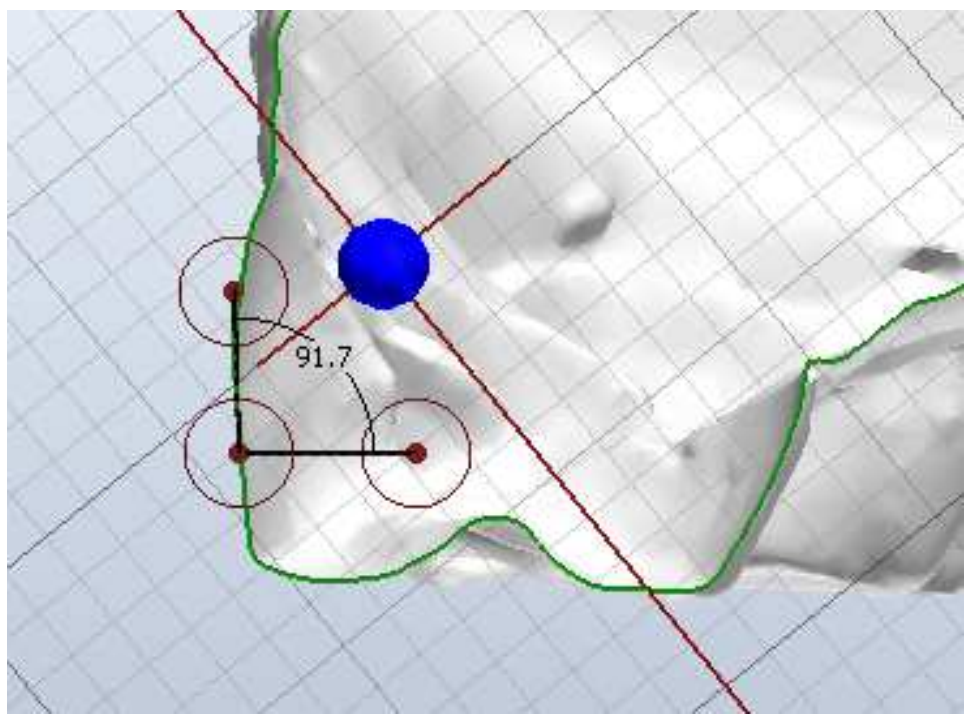

Figura 11: Corte Sagital do elemento 14 (substituto o 13) mostrando torque de $-1,7^{\circ}$. 


\subsubsection{Calibração do examinador}

Para avaliar a concordância intraexaminador, foi realizada uma segunda mensuração, em um intervalo de ao menos 10 dias, com $30 \%$ da amostra (selecionados randomicamente), considerando todas as variáveis desse tudo.

O menor valor do Kappa obtido foi de 0,83, com porcentagem de concordância de $85,68 \%$, portanto, sendo considerada concordância quase perfeita (Landis, Koch, 1977).

\subsection{ANÁLISE ESTATÍSTICA}

Cabe ressaltar que para o grupo FB, ambos os lados foram mensurados. Dessa forma, para cada elemento analisado (C, IL, IC), os dados apresentavam-se em duplicidade. Diante disso, para as análises propostas adotou-se o valor médio das mensurações entre os lados direito e esquerdo do paciente. Esse procedimento se fez necessário à comparação estatística entre grupos, uma vez que, tanto em SF quanto em FU, as medidas resultavam valores unitários, consequência lógica de avaliações unilaterais.

Outro aspecto relevante encontra-se no fato de que, por tratar-se do mesmo indivíduo, SF e FU tornam-se um mesmo grupo (SF+FU) quando da análise estatística do desnível entre IC nas variáveis distância vertical entre as bordas incisais e distância vertical entre as margens gengivais.

Dito isso, destaca-se que todos os dados obtidos das mensurações propostas

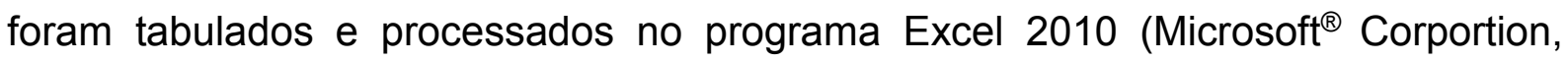
Redmont, WA, EUA), para serem analisados por meio do programa Software SigmaPlot for Windows versão 12.0 (Systat Software,San Jose, CA, USA), adotando-se 5\% como nível de significância.

No intuito de testar a hipótese de distribuição normal, em cada grupo e para todas as variáveis analisadas, o teste Shapiro-Wilk foi utilizado. Assim, para os dados não paramétricos, as comparações entre múltiplos grupos foram feitas através do teste Kruskall- Wallis complementado pelo método de Dunn's. Já para os dados que se mostraram paramétricos, utilizou-se o teste Anova complementado 
com o teste Tukey. Por fim, foram calculadas as médias e o desvio-padrão das variáveis analisadas. 


\section{Resultadas}





\section{RESULTADOS}

A composição amostral apresentou média de idade de 21 anos para SF e FU, enquanto para FB a média foi de 24 anos (Tabela 1). Relativo ao gênero e à raça, observa-se grande homogeneidade com predominância de homens brancos (Tabela 1).

Tabela 1: Descrição resumida dos membros pertencentes a cada grupo.

\begin{tabular}{ccccccc}
\hline \multirow{2}{*}{ Grupos } & Sujeitos & Idade & \multicolumn{2}{c}{ Gênero } & \multicolumn{2}{c}{ Raça } \\
& $(\mathbf{n})$ & $\mathbf{M}( \pm \mathrm{DP})$ & $\mathbf{M}$ & $\mathbf{F}$ & $\mathbf{B}$ & $\mathbf{N}$ \\
\cline { 4 - 7 } & & & & & & \\
\hline FU e SF & 59 & $21( \pm 3.25)$ & $37(63 \%)$ & $22(37 \%)$ & $58(98 \%)$ & $1(2 \%)$ \\
\hline FB & 41 & $24( \pm 3.59)$ & $28(68 \%)$ & $13(32 \%)$ & $39(95 \%)$ & $2(5 \%)$ \\
\hline Total & 100 & $22( \pm 3.7)$ & $65(65 \%)$ & $35(35 \%)$ & $97(97 \%)$ & $3(3 \%)$ \\
\hline
\end{tabular}

Legenda: M: masculino; F: feminino; B: branco; N: negro. Idade em média, n: número, DP: desvio padrão; SF: lado sem fissura; FU: fissura unilateral; FB: fissura bilateral.

$\mathrm{Na}$ tabela 2 constata-se diferença estatística $(p<0,05)$ entre FU e SF, havendo maiores médias das PL/H dos $\mathrm{C}$ e menores médias dos IC no grupo FU que no grupo SF. Observa-se também grande semelhança dos valores das PL/H dos IL para todos os grupos avaliados.

Tabela 2: Medidas correspondentes à proporção entre a largura e altura dentária do canino, incisivo lateral e central em cada grupo.

\begin{tabular}{|c|c|c|c|c|}
\hline \multirow{2}{*}{$\begin{array}{c}\text { Variáveis } \\
\text { analisadas }\end{array}$} & \multicolumn{3}{|c|}{ Grupos } & \multirow[b]{2}{*}{$p$} \\
\hline & SF & FU & FB & \\
\hline $\begin{array}{c}\text { Proporção da } \\
\text { largura e altura } \\
\text { do C }\end{array}$ & $0.83 \pm 0.09^{A}$ & $0.94 \pm 0.14^{\mathrm{B}}$ & $0.88 \pm 0.13^{A B}$ & $<0.001$ \\
\hline $\begin{array}{c}\text { Proporção da } \\
\text { largura e altura } \\
\text { do IL }\end{array}$ & $0.84 \pm 0.12^{A}$ & $0.84 \pm 0.12^{A}$ & $0.83 \pm 0.16^{A}$ & 0.262 \\
\hline $\begin{array}{c}\text { Proporção da } \\
\text { largura e altura } \\
\text { do IC }\end{array}$ & $0.86 \pm 0.08^{A}$ & $0.82 \pm 0.10^{B}$ & $0.85 \pm 0.12^{A B}$ & 0.040 \\
\hline
\end{tabular}


Para as PLA entre C/IL observou-se diferença $(p<0,05)$ com maiores PLA em SF que em FU e FB, enquanto entre IL/IC as proporções foram maiores e diferentes estatisticamente $(p<0,05)$ em FU comparados à SF. Há proximidade entre as medidas de SF e FB (Tabela 3).

Tabela 3: Medidas correspondentes à proporção da largura aparente em vista frontal do canino, incisivo lateral e central em cada grupo.

\begin{tabular}{ccccc}
\hline $\begin{array}{c}\text { Variáveis } \\
\text { analisadas }\end{array}$ & SF & FU & FB & p \\
\hline $\begin{array}{c}\text { Largura } \\
\text { aparente C/IL }\end{array}$ & $0.89 \pm 0.13^{\mathrm{A}}$ & $0.80 \pm 0.10^{\mathrm{B}}$ & $0.80 \pm 0.13^{\mathrm{B}}$ & $<0.001$ \\
\hline $\begin{array}{c}\text { Largura } \\
\text { aparente IL/IC }\end{array}$ & $0.73 \pm 0.06^{\mathrm{A}}$ & $0.77 \pm 0.09^{\mathrm{B}}$ & $0.74 \pm 0.09^{\mathrm{AB}}$ & 0.042 \\
\hline
\end{tabular}

Análise inter-grupos - teste Kruskall- Wallis complementado pelo método de Dunn's. Letras maiúsculas diferentes $=p<0,05$ para os grupos. SF: lado sem fissura; FU: fissura unilateral; FB: fissura bilateral. Medidas em porcentagem. $O$ incisivo central é referência para a proporção do incisivo lateral e este é referência para o percentual do canino.

No que se refere às DVB, ressalta-se diferença $(p<0,05)$ e os maiores desníveis entre IC e C em SF que em FU e FB. Observa-se também menores discrepâncias nas demais comparações entre grupos (Tabela 4).

Tabela 4: Medidas correspondentes às distâncias verticais entre as bordas incisais em cada grupo.

\begin{tabular}{|c|c|c|c|c|}
\hline \multirow{2}{*}{$\begin{array}{l}\text { Variáveis } \\
\text { analisadas }\end{array}$} & \multicolumn{3}{|c|}{ Grupos } & \multirow[b]{2}{*}{$\mathbf{p}$} \\
\hline & SF & FU & FB & \\
\hline $\begin{array}{c}\text { Entre bordas IC } \\
\text { e C }^{2}\end{array}$ & $-0.49 \pm 0.49^{A}$ & $-0.22 \pm 0.48^{B}$ & $-0.18 \pm 0.43^{B}$ & 0.001 \\
\hline $\begin{array}{c}\text { Entre bordas IC } \\
\text { e IL }{ }^{2}\end{array}$ & $0.25 \pm 0.42^{A}$ & $0.33 \pm 0.40^{\mathrm{A}}$ & $0.37 \pm 0.44^{A}$ & 0.384 \\
\hline & \multicolumn{2}{|c|}{ SF+FU } & FB & \\
\hline Entre bordas IC ${ }^{1}$ & \multicolumn{2}{|c|}{$-0.19 \pm 0.34^{A}$} & $-0.08 \pm 0.36^{A}$ & 0.153 \\
\hline
\end{tabular}

Quanto à DVM: para C, a DVM mostrou-se diferente $(p<0,05)$ entre todos os grupos, e nos IL houve diferença $(p<0,05)$ entre SF com FB e FU; além disso, a DVM entre IC apresentou diferença $(p<0,05)$ entre indivíduos com FTI unilateral $(\mathrm{SF}+\mathrm{FU})$ comparados com FB. Nesse sentido, tomando IC como referência, ocorre DVM dos C mais incisal na seguinte ordem: FU, FB e SF. Para IL, a DVM é menos 
incisal em FU e FB que em SF e entre IC-IC a DVM mostra menores desníveis em FB que em SF+FU (Tabela 5).

Tabela 5: Medidas correspondentes às distâncias verticais entre as margens gengivais do canino, incisivo lateral e central em cada grupo.

\begin{tabular}{|c|c|c|c|c|}
\hline \multirow{2}{*}{$\begin{array}{c}\text { Variáveis } \\
\text { analisadas }\end{array}$} & \multicolumn{3}{|c|}{ Grupos } & \multirow[b]{2}{*}{$\mathbf{p}$} \\
\hline & SF & FU & FB & \\
\hline $\begin{array}{l}\text { Entre margens } \mathrm{IC} \text { e } \\
\mathrm{C}^{1}\end{array}$ & $-1.32 \pm 0.96^{A}$ & $-2.86 \pm 0.98^{B}$ & $-2.11 \pm 1.33^{C}$ & $<0.001$ \\
\hline \multirow[t]{2}{*}{$\begin{array}{l}\text { Entre margens } \mathrm{IC} \text { e } \\
\mathrm{IL}_{1}\end{array}$} & $-1.39 \pm 0.95^{A}$ & $-0.86 \pm 1.07^{B}$ & $-0.53 \pm 1.09^{\mathrm{B}}$ & $<0.001$ \\
\hline & \multicolumn{2}{|c|}{ SF+FU } & FB & \\
\hline $\begin{array}{l}\text { Entre margens } \mathrm{IC} \mathrm{e} \\
\qquad \mathrm{IC}^{2}\end{array}$ & \multicolumn{2}{|c|}{$-0.69 \pm 0.77^{A}$} & $-0.15 \pm 0.99^{\mathrm{B}}$ & 0.003 \\
\hline
\end{tabular}

Da tabela 6, depreende-se a semelhança entre os valores registrados para ANG ( $p>0.05)$. Enquanto a INC se mostra menos acentuada vestibularmente nos IC e IL dos indivíduos com FTI bilateral que aqueles com FTI unilateral. Existindo diferença $(p<0.05)$ entre FU e FB. Contudo, há proximidade clínica nos torques vestibulares de FU e SF (Tabela 7).

Tabela 6: Medidas correspondentes à angulação do canino, incisivo lateral e central em cada grupo.

\begin{tabular}{lcccc}
\hline \multicolumn{1}{c}{$\begin{array}{c}\text { Variáveis } \\
\text { analisadas }\end{array}$} & SF & FU & FB & prupos \\
\hline $\begin{array}{c}\text { Angulação do } \\
\text { C }\end{array}$ & $3.89 \pm 2.83^{\mathrm{A}}$ & $4.16 \pm 3.27^{\mathrm{A}}$ & $3.95 \pm 3.24^{\mathrm{A}}$ & 0.774 \\
\hline $\begin{array}{l}\text { Angulação do } \\
\text { IL }\end{array}$ & $2.94 \pm 2.90^{\mathrm{A}}$ & $2.81 \pm 3.12^{\mathrm{A}}$ & $3.38 \pm 3.31^{\mathrm{A}}$ & 0.702 \\
\hline $\begin{array}{l}\text { Angulação do } \\
\text { IC }\end{array}$ & $1.08 \pm 2.06^{\mathrm{A}}$ & $0.36 \pm 2.32^{\mathrm{A}}$ & $0.52 \pm 1.85^{\mathrm{A}}$ & 0.201 \\
\hline $\begin{array}{l}\text { Análise inter-grupos }- \\
\text { diferentes }=\text { teste Kruskall- Wallis complementado pelo método de Dunn's. Letras maiúsculas } \\
\text { graus. }\end{array}$
\end{tabular}


Tabela 7: Medidas correspondentes à inclinação (torque) do canino, incisivo lateral e central em cada grupo.

\begin{tabular}{|c|c|c|c|c|}
\hline \multirow{2}{*}{$\begin{array}{c}\text { Variáveis } \\
\text { analisadas }\end{array}$} & \multicolumn{3}{|c|}{ Grupos } & \multirow[b]{2}{*}{$\mathbf{p}$} \\
\hline & SF & FU & FB & \\
\hline $\begin{array}{c}\text { Inclinação do } \\
\text { C }\end{array}$ & $-0.75 \pm 6.18^{\mathrm{A}}$ & $-0.25 \pm 5.65^{A}$ & $-1.99 \pm 6.33^{A}$ & 0.441 \\
\hline $\begin{array}{l}\text { Inclinação do } \\
\text { IL }\end{array}$ & $6.37 \pm 5.97^{A B}$ & $7.05 \pm 6.95^{\mathrm{A}}$ & $3.79 \pm 6.69^{B}$ & 0.048 \\
\hline $\begin{array}{c}\text { Inclinação do } \\
\text { IC }\end{array}$ & $6.58 \pm 6.27^{A B}$ & $7.78 \pm 6.42^{\mathrm{A}}$ & $4.37 \pm 7.28^{B}$ & 0.042 \\
\hline
\end{tabular}


Discussãa 



\section{DISCUSSÃO}

Esse estudo contou com modelos digitais de 100 pacientes, sendo 59 do grupo FU e SF, e 41 para o grupo FB (Anexos 1 e 2). A composição amostral, tanto em relação à idade (FU e SF: 21 anos; FB: 24 anos), quanto ao gênero (FU e SF: $63 \%$ homens e $37 \%$ mulheres; FB: $68 \%$ homens e $32 \%$ mulheres) e raça, (FU e SF: $98 \%$ brancos e $2 \%$ negros; FB: $95 \%$ brancos e $5 \%$ negros) apresentam grande homogeneidade entre si, conforme nota-se na tabela 1.

Ressalta-se ainda que a amostra avaliada é composta de adultos jovens com FTI unilateral (considerado também o lado sem fissura) ou bilateral, cujo tratamento reabilitador envolveu as cirurgias primárias de lábio e palato, EOAS, tratamento ortodôntico, sem próteses sobre dentes ou implantes na região intercaninos superior, e que em sua maioria define-se por: indivíduos submetidos à cirurgia ortognática e/ou reanatomiazações por acréscimo ou desgaste nos dentes caninos, incisivos laterais e incisivos centrais. Cabe salientar ainda que os dentes submetidos à análise são aqueles nas posições ocupadas por esses dentes, sendo ou não os referidos elementos (Anexos 1 e 2). Dessa forma, para maior clareza, as siglas IC, IL e C serão utilizadas para se referir aos dentes nas posições em que habitualmente se encontram, respectivamente, incisivos centrais, incisivos laterais e caninos, enquanto a notação numérica (ex. 11,12,13 e 14) refere-se esses dentes propriamente ditos.

Em contraposição à literatura direcionada à reabilitação e descrição estética do paciente sem FLP, pouco se tem publicado quanto às mesmas características em pacientes com FLP. Portanto, o presente trabalho se preocupou em descrever e analisar os seguintes aspectos da microestética dentária intercanina superior de paciente com FTI unilateral (SF e FU) ou bilateral (FB): proporção entre largura e altura dentária(PL/H); proporção da largura aparente em vista frontal (PLA); distância vertical entre as bordas incisais (DVB); distância vertical entre as margens gengivais (DVM); angulação da coroa dentária (ANG); inclinação da coroa dentária torque(INC). 
Proporção entre largura e altura dentária (Tabela 2)

O lado com fissura (FU), comparativamente ao sem fissura (SF), apresenta maiores PL/H nos C (SF: $0.83 \mathrm{~mm}$; FU: $0.94 \mathrm{~mm}$ ) e menores nos IC (SF: $0.86 \mathrm{~mm}$; FU: $0.82 \mathrm{~mm}$ ). No primeiro caso $(\mathrm{C})$, destaca-se a agenesia dos incisivos laterais, comuns em indivíduos com FLP (49,5\%) e predominante na amostra (Anexos 1 e 2), assim como a substituição do dente 13 e/ou 23 pelo 14 e/ou 24 no lado com fissura (LOURENÇO et al., 2003; FREITAS et al., 2012; DALBEN; LAURIS; ALMEIDA, 2013; FREITAS et al., 2013), isso porque, naturalmente, pré-molares são dentes com coroas clínicas mais quadradas que caninos e consequentemente a PL/H do C apresenta maiores valores do lado da fissura - inclusive em FB: 0.88 mm.(MAGNE; GALLUCCI; BELSER, 2003; SAVER, 2004). No segundo caso (IC), as menores $\mathrm{PL} / \mathrm{H}$ potencialmente estão relacionadas às recessões gengivais, comuns nos dentes adjacentes à fissura e com alta prevalência nos IC na amostra analisada Anexos 1 e 2 (ALMEIDA et al., 2007). Por fim, infere-se haver assimetria entre os lados com e sem fissura quanto à $\mathrm{PL} / \mathrm{H}$ em indivíduos com FTI unilateral, evidenciada pelos valores médios e pela diferença estatística constatada $(p<0.001)$.

Interessante avaliar que, mesmo diante da substituição de incisivos laterais por caninos na região da fissura, a PL/H dos IL mostrou-se com valores semelhantes para todos os grupos, inclusive em SF, grupo em que a referida substituição não acontece (Anexos 1 e 2) Dessa forma, os resultados aqui obtidos corroboram estudos quanto à semelhança da $\mathrm{PL} / \mathrm{H}$ de incisivos laterais com caninos superiores 73 - 83\% (GILLEN et al., 1994; MAGNE; GALLUCCI; BELSER, 2003).

Além disso, do ponto de vista da agradabilidade estética, a largura dos incisivos centrais superiores deve ser próxima de $80 \%$ da altura dos mesmos (PROFFIT; SARVER; ACKERMAN, 2007). Logo, se considerado apenas a PL/H, a média apurada para o grupo FU seria a mais estéticas. 


\section{Proporção da largura aparente em vista frontal (Tabela 3)}

Com relação às PLA dos dentes em análise, observa-se novamente diferença entre os valores auferidos para as regiões com fissura (FU e FB) e sem fissura (SF). Nesse sentido, tratando-se das PLA dos C/IL, verifica-se maiores proporções em SF (SF: $0.89 \mathrm{~mm}$; FU: $0.80 \mathrm{~mm}$; FB: $0.80 \mathrm{~mm}$ ). Tal fato relaciona-se à presença dos elementos 12 e/ou 22 e consequente manutenção dos caninos em seus lugares habituais no grupo SF. Assim, enquanto em SF a relação C/IL refere-se a PLA entre caninos (13 e/ou 23) e incisivos laterais (12 e/ou 22), essa mesma relação em FU e FB dá-se entre $1^{\circ}$ pré-molares (C) e caninos (IL). Dessa forma, como os caninos são naturalmente mais largos que os incisivos laterais, e os pré-molares tem larguras semelhantes às dos caninos, a PLA dos C/IL apresenta-se diminuída do lado com fissura.(MAGNE; GALLUCCI; BELSER, 2003; FREITAS et al, 2012).

Quando a variável em análise é a PLA dos IL/IC, a diferença mostra-se mais acentuada entre os lados com fissura (FU) e sem fissura (SF) nos indivíduos com FTI unilateral (SF: $0.73 \mathrm{~mm}$; FU: $0.77 \mathrm{~mm}$; FB: $0.74 \mathrm{~mm}$ ). Aqui a análise a ser feita remete àquela dada para a PLA dos C/IL. Contudo, nesse caso o IC é uma constante (devido à proximidade das larguras do 11 e 21) e como os caninos, substitutos dos laterais em FU (Anexos 1 e 2), são naturalmente mais largos que incisivos laterais tem-se como resultado proporporções maiores na região da fissura (MAGNE; GALLUCCI;; BELSER, 2003; FREITAS et al., 2012). Essa situação também denota assimetria entre as PLA de lados contralaterais nos indivíduos com FTI unilateral.

Outro fato curioso diz respeito às semelhanças na PLA dos IL/IC nos grupos SF e FB (SF:0.73 mm; FB:0.74 mm). Essa situação, provavelmente, relaciona-se às reanatomizações, comuns quando se substiui ortodonticamente incisivos laterais por caninos e estes por pré-molares tais reanatomizações também estão mais prevalentes no grupo FB (Anexos 1 e 2) resultando na proximidade com SF, enquanto FU mostra-se estatisticamente diferente - $p<0.05$ (ZACHRISSON; ROSA; TORESKOG, 2011).

Embora a agenesia do incisivo lateral seja a característica determinante das diferenças acima discutidas, ela não está presente no grupo SF e ainda assim os 
valores médios (SF: $\mathrm{C} / \mathrm{IL}=0.89 ; \mathrm{IL} / \mathrm{IC}=0.73$ ) estão distantes daqueles reportados para a proporção áurea $-\mathrm{C} / \mathrm{IL}=62 \%$; IL/IC $=62 \%$ (PROFFIT; SARVER; ACKERMAN, 2007). No entanto, os dados aqui obtidos corroboram estudos que reportaram ser raramente encontrada a proporção áurea na dentição natural (PRESTON ,1993; GILLEN et al., 1994).

Distância vertical entre as bordas incisais (Tabela 4)

Da análise dos dados observa-se que, em média, o $C$ é mais proeminente do lado sem fissura (SF: -0,49 mm) que do lado com fissura (FU: -0,22 mm; FB: - 0,18 $\mathrm{mm}$ ). Esse resultado também se relaciona às substituições de incisivos laterais $e$ caninos, como já relatado (LOURENÇO et al., 2003; DALBEN; LAURIS; ALMEIDA, 2013; FREITAS et al., 2012; FREITAS et al., 2013). E se compreende pela anatomia mais proeminente dos caninos (nos seus locais habituais em SF) em relação aos pré-molares (substitutos dos caninos em FU e FB) (PROFFIT; SARVER; ACKERMAN, 2007; ZACHRISSON; ROSA; TORESKOG, 2011). Soma-se a isso a ausência, na amostra, dos elementos 14 e/ou 24 reanatomizados por acréscimo de resina composta (Anexos 1 e 2).

Por outro lado, nas demais medidas da DVB observa-se baixa discrepância nas comparações entre grupos, de maneira que os desníveis entre IC e IL mostramse similares na região em que ocorre a fissura (FU e FB) comparativamente à SF (SF: $0.25 \mathrm{~mm}$, FU: $0.33 \mathrm{~mm}$; FB: $0.37 \mathrm{~mm}$ ). Tal homogeneidade pode ser explicada pelas reanatomizações por desgaste na incisal do canino, procedimento comum na mimetização estética desses dentes quando na posição dos laterais, assim como frequentes na amostra ora analisada - anexos 1 e 2 (ZACHRISSON; ROSA; TORESKOG, 2011). Também não há discrepância relevante no degrau entre IC em indivíduos com FTI bilateral (FB:- $0.08 \mathrm{~mm}$ ) comparados aos com FTI unilateral (SF+FU: $-0.19 \mathrm{~mm}$ )

Outro ponto importante a destacar refere-se à adequação estética da DVB. Nesse aspecto, dos resultados deste trabalho, salienta-se a posição mais proeminente dos $\mathrm{C}$ em relação aos $\mathrm{IC}$, portanto inversa ao considerado mais agradável esteticamente, uma vez que as incisais dos incisivos centrais superiores 
devem ficar abaixo da ponta de cúspide dos caninos (MACHADO, 2014). Também pode-se observar inadequação estética da amostra (65\% homens e DVB = SF: 0.25 $\mathrm{mm}$; FU: $0.33 \mathrm{~mm}$; FB: $0.37 \mathrm{~mm}$, todas apicais ao IC) frente à agradabilidade suscitada pelo degrau entre IC e IL, o qual preferencialmente devem ser de 1 a 1,5 $\mathrm{mm}$ para mulheres e de 0,5 a $1 \mathrm{~mm}$ para homens. Somadas, essas características denotam desfavorecimento ao contorno do arco do sorriso e a dominância dos incisivos centrais superiores, elementos chave no design do sorriso (MACHADO, 2013; MACHADO, 2014).

Contrariamente, quanto à DVB dos IC (SF+FU: $0.19 \mathrm{~mm}$; FB: $0.08 \mathrm{~mm})$ os resultados deste estudo apresentam-se adequados aos parâmetro estético, já que em média as DVB dos IC são menores que 0,5 mm (MACHADO, 2013).

Distância vertical entre as margens gengivais (Tabela 5)

A DVM dos C de todos os grupos encontra-se incisal ao IC (SF:-1.32 mm; FU: $-2.86 \mathrm{~mm}$; FB: $-2.11 \mathrm{~mm}$ ), de forma que ocorrem maiores medidas (mais incisais) na região com fissura. Esses resultados, possivelmente, são decorrentes da substituição do canino pelo $1^{\circ}$ pré-molar. Como o $1^{\circ}$ pré-molar apresenta coroa mais curta, projeção incisal quando na posição dos caninos (Tabela 4), e ainda pela ausência de reanatomizações por acréscimo de resina no 14 ou 24 (Anexos 1 e 2), tem-se, como consequência lógica, margens gengivais dos pré-molares (C) mais incisais nas regiões com fissura - FU e FB (MAGNE; GALLUCCI; BELSER, 2003; FREITAS et al., 2012; FREITAS et al., 2013).

Já na DVM dos IL com IC (referência) observa-se degraus maiores em SF que em FU e FB (SF:-1.39 mm; FU:-0.86 mm; FB:-0.53 mm). Essa característica correlaciona-se ao alto índice de recessão gengival na região da fissura, uma vez que essa condição é 10 vezes mais prevalente em indivíduos com FLP e encontrase com grande frequência na amostra analisada - anexos 1 e 2. (ALMEIDA et al., 2007) Essa análise também cabe à diferença $(p<0,05)$ notada na DVM dos IC de invidivíduos com FTI bilateral (FB) em relação àqueles com FTI unilateral (SF+FU). Dessa forma, como as recessões são mais frequentes do lado com fissura e essa se 
apresenta unilateral em SF+FU, observa-se maiores DVM dos IC para esse grupo (ALMEIDA et al., 2007).

Quando o padrão estético é avaliado, pesquisa anterior em pacientes com FTI unilateral mostra que, ao avaliar o lado sem fissura, 47,4\% desses indivíduos apresentaram exposição de tecido gengival em algum nível (de apenas ameias gengivais a até $2 \mathrm{~mm}$ de exposição). Já no lado com fissura, o percentual reportado foi de 35,92\% (ESPER et al., 2012). Portanto evidencia-se a participação do componente gengival na estética do sorriso.

Assim, em relação à margem gengival dos $\mathrm{C}$, em todos os grupos ela não se posiciona no mesmo nível do IC, portanto apresenta padrão distinto do definido na literatura como esteticamente preferível (PROFFIT; SARVER; ACKERMAN, 2007). Além disso, uma vez que alterações do nível da margem gengival dos caninos em relação ao incisivo central de apenas um dos lados são percebidas como antiestéticas a partir de $2 \mathrm{~mm}$ de desnível, verifica-se na amostra característica diferente desse padrão, pelo menos para o grupo FU - unilateral e FU: $-2.86 \mathrm{~mm}$ (CORREA, BITTENCOURT; MACHADO; 2014).

Para as demais variáveis encontra-se harmonia estética, pois o degrau médio verificado entre IC e IL (-1.39 mm), para o grupo SF, está clinicamente próximo do definido como mais estético na literatura - 1,5 mm (PROFFIT; SARVER; ACKERMAN, 2007). Por outro lado, médias mais distantes, com menor degrau, são encontradas para os grupos FU e FB. Contudo, estudo anterior, tendo $1 \mathrm{~mm}$ como referência, reporta que variações de até $2 \mathrm{~mm}$ na DVM dos incisivos laterais com incisivos centrais não influencia na observação estética do sorriso (KOKICH, 1999).

Para a DVM dos IC (SF+FU:-0.69 mm; FB: $-0.15 \mathrm{~mm}$ ), embora haja assimetria mais acentuada nos pacientes com FTI unilateral, somente assimetrias maiores de 1,5 mm são avaliadas como esteticamente menos atrativas $(\mathrm{KOKICH}$; KOKICH; KIYAK, 2006). Assim, deve-se fazer uma avaliação criteriosa frente ao binômio tratar ou não tratar discrepâncias menores que a descrita acima. (MACHADO; MOON e GANDINI, 2013) 
Angulação da coroa dentária (Tabela 6)

Esse aspecto da microestética dentária refere-se ao posicionamento angular mesio-distal do dente, tomando como referência o longo-eixo da coroa do elemento avaliado (ANDREWS, 1972). Para essa variável, diante dos resultados obtidos em nosso trabalho, não se constatou diferença entre os grupos $(p>0,05)$. Portanto, verificou-se semelhança entre as regiões com e sem fissura.

Esse resultado potencialmente decorre da presença do EOAS na região da fissura, cujo índice de sucesso supera 80\% (BERGLAND, SEMB; ABYHOLM, 1986; TRINDADE et al., 2005, FREITAS et al., 2012). Nesse sentido, estando a fissura preenchida com osso, possibilita-se um melhor posicionamento das raízes na base óssea e consequente adequação da angulação da coroa dentária na região da fissura comparativamente à sem fissura (SILVA FILHO et al., 2000; FREITAS et al., 2012)

Interessante observar que os resultados aqui apresentados para a ANG diferem dos valores esperados, pois os braquetes mais utilizados no setor de ortodontia do HRAC-USP tem prescrição de +8 , +9 e +5 , respectivamente, para caninos, incisivos laterais e incisivos centrais. Vários fatores podem estar envolvidos nesses resultados, dentre os quais se destacam as posições dos dentes pré tratamento ortodôntico, tais como as contra-angulações e as giroversões, assim como as substituições dos incisivos laterais por caninos e desses por pré-molares na região da fissura, situações comuns em indivíduos com FLP (TRINDADE; SILVA FILHO, 2000; FREITAS et al., 2012) e que podem influenciar o posicionamento do braquete ortodôntico e consequentemente a angulação final da coroa dentária.

Outro ponto passível de influência infere-se do padrão III de crescimento da face, comum tanto na população de indivíduos com FLP completa , como também na amostra - anexos 1 e 2 (SEMB, 1991; CAPELOZZA; NORMANDO; SILVA FILHO, 1996; FREITAS et al., 2012). Nela, essa ocorrência é evidenciadapela frequência de cirurgias de avanço maxilar, o que nos permite concluir haver severa deficiência maxilar nesses pacientes. Portanto, ocorrem compensações de ângulo e torque dentário (prévias à ortodontia) decorrentes do crescimento alterado, como indica o índice Goslon e sua modificação por Atack , assim como o índice para a avaliação 
do arco dentário em fissuras bilaterais (MARS, 1987; ATACK, 1997; OZAWA, 2011). Esses fatos, somados ao poder retrusivo das cicatrizes decorrentes da queiloplatia (CAPELOZZA; NORMANDO; SILVA FILHO, 1996; FREITAS et al, 2012), determinariam, durante a colagem, alinhamento e nivelamento ortodôntico, correções de anglo e torque parciais, ou seja, sem total expressão da angulação e torque embutidos nos braquetes.(ODEGAARD; MELING; MELING, 1994; ARCHAMBAULT et al., 2010).

Observa-se ainda que as prevalentes recessões gengivais (Anexo 1 e 2), que potencialmente alteram a posição do zênite gengival, e as reanatomizações, que alteram plasticamente a forma das coroas dentárias, podem influenciar a percepção da angulação dos dentes, tanto no momento da colagem do braquete ortodôntico, quanto durante a aplicação da metodologia aqui desenvolvida (ALMEIDA et al., 2007; BHUVANESWARAN, 2010; ZACHRISSON; ROSA; TORESKOG, 2011).

Por fim, quanto aos parâmetro estéticos, no que se refere ao IC, estudo anterior reporta que angulações de $0^{\circ},-2^{\circ}$ e $+2^{\circ}$ são, nessa ordem, as mais atrativas (YANG et al., 2015). Diante disso, observa-se coincidência entre os resultados deste trabalho (SF: $1.08^{\circ}$; FU: $0.36^{\circ}$; FB: $0.52^{\circ}$ ) e a literatura recente.

Inclinação da coroa dentária - torque. (Tabela 7).

A inclinação dentária ou torque refere-se ao posicionamento angular vestíbulo-lingual ou vestíbulo-palatino da coroa dentária cuja referência coincide com a descrita para a angulação (ANDREWS, 1972). Cabem aqui as mesmas considerações feitas para a variável ANG, quanto às características de posicionamento dentário, de forma dentária, influência do padrão de crescimento e cicatrizes (MARS, 1987; SEMB, 1991; CAPELOZZA; NORMANDO e SILVA FILHO, 1996; ATACK, 1997; OZAWA, 2011; FREITAS et al., 2012). Isso porque os resultados aqui apresentados também diferenciam-se daqueles esperados, já que a prescrição ortodôntica mais utilizada no HRAC-USP prevê torques de $-5,+3$ e +7 , respectivamente, para caninos, incisivos laterais e incisivos centrais.

No que se refere à comparação entre os grupos, constatou-se IC e IL com INC vestibulares menos acentuadas em FB que em FU. Nesse sentido, pode-se 
observar grande semelhança clínica entre os torques desses dentes nos grupos SF e FU. Tratando-se de grupos que representam os mesmos indivíduos, evidencia-se que o lado SF acaba por determinar maior estabilidade no posicionamento sagital dos dentes antero-superiores, determinando menor perda de torque durante a mecânica ortodôntica no lado FU comparativamente ao grupo FB. Nesses últimos, as agenesias de incisivos laterais bilateralmente acabam por diminuir, antes do fechamento dos espaços, a estabilidade sagital. Consequentemente, perde-se torque vestibular no decorrer da reabilitação ortodôntica, uma vez que os incisivos centrais ficam mais susceptíveis à força retrusora do lábio superior, a qual se apresenta potencializada no paciente com FLP devido às cicatrizes da queiloplastia. (WOODWORTH; SINCLAIR; ALEXANDER, 1985; MARS, 1987; SEMB, 1991; CAPELOZZA; NORMANDO e SILVA FILHO, 1996; ATACK, 1997; OZAWA, 2011; FREITAS et al., 2012 )

Em relação aos $C$ nota-se similaridade dos torques entre as regiões com fissura (FU e FB) e sem fissura (SF). Além do mais, os C (em média) apresentam-se com torques muito maiores que o definido pela prescrição habitualmente utilizada (5). Esse fato pode estar relacionado às terapêuticas protocolares no HRAC-USP: uso do Hyrax ou Hass para correção da deficiência maxilar transversal, frequente em indivíduos com FLP completas, e posterior uso da contenção tipo 3D (barra transpalatina com ancoragem em molares e extensões até a região de caninos) durante a mecânica com braquetes (FREITAS et al., 2012). Esses procedimentos possivelmente determinariam a expressão parcial dos torques dos braquetes

O aspecto anatômico dos caninos, quando substitutos dos incisivos laterais, também pode interferir no torque. Pois, além de reanatomizações por desgaste na palatina, a correção do torque vestibular da coroa desse elemento também é necessária, de maneira a mimetizar a inclinação própria dos incisivos laterais e se obter o melhor resultado estético (ZACHRISSON; ROSA; TORESKOG, 2011).

Por fim, dos resultados deste trabalho observa-se predominância de torques vestibulares para IC e IL. Logo, favorece-se o arco do sorriso, dado que inclinações palatinas promovem o achatamento do referido arco e a diminuição da exposição dos incisivos (SARVER, 2001). Além disso, torques de $+5^{\circ}$ para os incisivos superiores são tidos como os mais atraente (CAO et al., 2011), valor semelhante clinicamente aos achados do presente trabalho (SF: 6.58; FU: $7.78^{\circ}$; FB: $4.37^{\circ}$ ). 
De todo exposto, destaca-se que, do ponto de vista funcional, em paciente com FLP com agenesia IL e envolvimento do rebordo alveolar, o padrão ouro na reabilitação ortodôntica do HRAC-USP parece ser o fechamento de espaços com a mesialização do canino, substituindo o incisivo lateral, e com o $1^{\circ}$ pré-molar na posição do canino pós EOAS (FREITAS et al., 2012; FREITAS et al., 2013; DALBEN, LAURIS, ALMEIDA, 2013). Esteticamente, do presente trabalho, observase que grande parte das alterações observadas na microestética dos elementos antero-superiores (não necessariamente desagradáveis) advieram justamente da proposta padrão de reabilitação funcional deste Centro, que se soma às características definidas pela própria fissura, com particular ênfase às recessões gengivais nos dentes adjacentes à fissura (ALMEIDA et al., 2007).

A ausência de literatura correspondente à temática aqui discutida, específica para pacientes com FLP, é fator limitante para uma comparação mais precisa das análises desse trabalho. Portanto, nosso estudo tem um grande papel: fomentar a discussão e, posteriormente, servir como base para que novos trabalhos possam ser realizados com pacientes com FLP. Outra limitação encontra-se na metodologia aplicada, pois outros aspectos importantes da microestética dentária, tais como: pontos de contato, ameias gengivais, triângulos negros; tonalidade e cor dos dentes (PROFFIT; SARVER e ACKERMAN, 2007) não se mostraram fidedignos nos modelos digitais analisados. Por isso, sugere-se que novos trabalhos avaliem esses outros aspectos, e que também busquem correlacionar a reabilitação estética da face de indivíduos com FLP ao bem estar e qualidade de vida dela decorrente. 
Canclusãa 



\section{CONCLUSÕES}

Os resultados desse trabalho não dão suporte à hipótese nula sugerida, posto que concluiu-se haver, em adultos jovens após o tratamento ortodôntico, diferenças na microestética dentária da região com fissura (FU e/ou FB) quando comparada à sem fissura (SF). Inclusive existem diferenças entre a região da fissura de indivíduos com FTI unilateral (FB) e aqueles com FTI bilateral (FB). Notadamente,

- na PL/H: há maiores proporções para C e menores para IC em FU que em SF.

- Quanto à PLA: entre C/IL encontrou-se valores maiores em SF que em FU e FB, e entre IL/IC, a PLA do grupo FU foi maior que a do SF.

- Relativo à DVB: constatou-se C mais proeminentes em SF que em FU e FB.

- Correspondente à DVM: tomando IC como referência, as DVM dos C são mais incisais na seguinte ordem: FU, FB e SF; para IL e a mesma referência (IC), há menores DVM em FU e FB que em SF; e a DVM dos IC apresenta menores desníveis em FB que em SF+FU.

- Na INC: IL e IC apresentaram torques vestibulares menos acentuados em FB que em FU. 



\section{Referências}





\section{REFERÊNCIAS}

Ackerman MB, Brensinger C, Landis JR. An evaluation of dynamic lip-tooth characteristics during speech and smile in adolescents. Angle Orthod. 2004 Feb;74(1):43-50.

Almeida, A. L. P. F. D., Madeira, L. C., Freitas, K. C. D., Greghi, S. L. A., \& Pegoraro, L. F. Cross-sectional evaluation of the presence of gingival recession in individuals with cleft lip and palate. Journal of periodontology. 2007 Jan; 78(1): 29-36.

Andrews LF. The six keys to normal occlusion. Am J Orthod. 1972 Sep;62(3):296309.

Andrews LF, Andrews WA. Andrews foundation syllabus of the Andrews orthodontic philosophy. 1st ed., 1991; revised and edited, 1994; revised and edited in subsequent editions; 4th ed., 1995; 8th ed. (1999) through 9th ed. (2001).

Atack N, Hathorn I, Mars M, Sandy J. Study models of 5 year old children as predictors of surgical outcome in unilateral cleft lip and palate. Eur J Orthod. 1997 Apr;19(2):165-70.

Archambault A, Major T, Carey J, Heo G, Badawi H, Major P. A comparison of torque expression between stainless steel, titanium molybdenum alloy, and copper nickel titanium wires in metallic self-ligating brackets. Angle Orthod. 2010;80(5):884-889. doi:10.2319/102809-604.1.

Bagheri SC, Jo C. Clinical Review of Oral and Maxillofacial Surgery. Elsevier Health Sciences, 2013. p. 463.

Bennett JC; Mclaughlin RP. O tratamento ortodôntico da dentição com o aparelho pré-ajustado. Artes Médicas, 1998.

Bergland O, Semb G, Abyholm FE. Elimination of the residual alveolar cleft by secondary bone grafting and subsequent orthodontic treatment. Cleft Palate J. 1986 Jul;23(3):175-205. 
Bhuvaneswaran M. Principles of smile design. J Conserv Dent. 2010 Oct;13(4):22532. doi: 10.4103/0972-0707.73387.

Borges ACG, Seixas MR, Machado AW. Influence of different width/height ratio of maxillary anterior teeth in the attractiveness of gingival smiles. Dental Press Journal of Orthodontics, 17(5), 115-122, 2012. https://dx.doi.org/10.1590/S2176$\underline{94512012000500016 .}$.

Bothung C, Fischer K, Schiffer H, Springer I, Wolfart S. Upper canine inclination influences the aesthetics of a smile. J Oral Rehabil. 2015 Feb;42(2):144-52. doi: 10.1111/joor.12234.

Brandão RCB; Brandão LBC. Finishing procedures in Orthodontics: dental dimensions and proportions (microesthetics). Dental Press Journal of Orthodontics, 18(5), 147-174, 2013. https://dx.doi.org/10.1590/S2176-94512013000500006

Bull R, Rumsey N. The Social Psychology of Facial Appearance. Springer Science \& Business Media. 2012; 355.

Calvo MG, Gutiérrez-García A, Avero P, Lundqvist D. Attentional mechanisms in judging genuine and fake smiles: eye-movement patterns. Emotion. 2013 Aug;13(4):792-802. doi: 10.1037/a0032317.

Capelozza Filho L, Correa Normando A, da Silva Filho O. Isolated Influences of Lip and Palate Surgery on Facial Growth: Comparison of Operated and Unoperated Male Adults with UCLP. Cleft Palate Craniofac J. 1996;33(1):51-56. doi:10.1597/1545-1569(1996)033<0051:iiolap>2.3.co;2.

Cao, $\mathrm{Li}$ et al. Effect of maxillary incisor labiolingual inclination and anteroposterior position on smiling profile esthetics. The Angle Orthodontist, v. 81, n. 1, p. 121-129, 2011.

Cao L, Zhang K, Bai D, Jing Y, Tian Y, Guo Y. Effect of maxillary incisor labiolingual inclination and anteroposterior position on smiling profile esthetics. Angle Orthod. 2011 Jan;81(1):121-29. doi: 10.2319/033110-181.1. 
Charruel S, Perez C, Foti B, Camps J, Monnet-Corti V. Gingival contour assessment: clinical parameters useful for esthetic diagnosis and treatment. J Periodontol. 2008 May;79(5):795-801. doi: 10.1902/jop.2008.070488 .

Chu SJ, Tan JH, Stappert CF, Tarnow DP. Gingival zenith positions and levels of the maxillary anterior dentition. J Esthet Restor Dent. 2009;21(2):113-20. doi: 10.1111/j.1708-8240.2009.00242.x.

Correa BD, Vieira Bittencourt MA, Machado AW. Influence of maxillary canine gingival margin asymmetries on the perception of smile esthetics among orthodontists and laypersons. Am J Orthod Dentofacial Orthop. 2014 Jan;145(1):5563. doi: 10.1016/j.ajodo.2013.09.010.

Cunliffe J, Pretty I. Patients' ranking of interdental "black triangles" against other common aesthetic problems. Eur J Prosthodont Restor Dent. 2009 Dec;17(4):17781.

Dalben G., Lauris Almeida RC. Dental Rehabilitation of cleft lip and palate in the diferente stages of life. In: Jaso, N; D’Cruz AM. Cleft lip and palate: Etiology, Surgery \& Repair and Sociopsychological consequences. $1^{\mathrm{a}}$ Ed. Nova Biomedical, New York,2013.p55 - 92

Dickins S, Sarver DM, Proffit WR. The dynamics of the maxillary incisor and the upper lip: a cross-sectional study of resting and smile hard tissue characteristics. World J Orthod 2002;3:313-20.

Dixon MJ, Marazita ML, Beaty TH, Murray JC. Cleft lip and palate: understanding genetic and environmental influences. Nat Rev Genet. 2011 Mar;12(3):167-78. doi: 10.1038/nrg2933.

Dunn WJ, Murchison DF, Broome JC. Esthetics: patients' perceptions of dental attractiveness. J Prosthodont. 1996 Sep;5(3):166-71.

Esper LA, Sbrana MC, Cunha MJ, Moreira GS, de Almeida AL. Esthetic composition of smile in individuals with cleft lip, alveolus, and palate: visibility of the periodontium and the esthetics of smile. Plast Surg Int. 2012;2012:563734. doi: $10.1155 / 2012 / 563734$. 
Flanary C. The psychology of appearance and the psychological impact of surgical alteration of the face. In: Bell WH. Modern practice in orthognathic and reconstructive surgery. Philadelphia: W.B. Saunders; 1992. p.2-21.

Freitas JA, das Neves LT, de Almeida AL, Garib DG, Trindade-Suedam IK, Yaedú RY, Lauris Rde C, Soares S, Oliveira TM, Pinto JH. Rehabilitative treatment of cleft lip and palate: experience of the Hospital for Rehabilitation of Craniofacial Anomalies/USP (HRAC/USP)--Part 1: overall aspects. J Appl Oral Sci. 2012 Feb;20(1):9-15.

Freitas J, Garib D, Oliveira M et al. Rehabilitative treatment of cleft lip and palate: experience of the Hospital for Rehabilitation of Craniofacial Anomalies - USP (HRACUSP) - Part 2: Pediatric Dentistry and Orthodontics. J Appl Oral Sci. 2012;20(2):268281. doi:10.1590/s1678-77572012000200024.

Freitas JA, Almeida AL, Soares S, Neves LT, Garib DG, Trindade-Suedam IK, Yaedú RY, Lauris Rde C, Oliveira TM, Pinto JH. Rehabilitative treatment of cleft lip and palate: experience of the Hospital for Rehabilitation of Craniofacial Anomalies/USP (HRAC/USP) - Part 4: oral rehabilitation. J Appl Oral Sci. 2013;21(3):284-92. doi: 10.1590/1679-775720130127.

Frush JP, Fisher RD. The dynesthetic interpretation of the dentogenic concept. The Journal of Prosthetic Dentistry. 1958; 8(4):558-581.

Geron S, Atalia W. Influence of sex on the perception of oral and smile esthetics with different gingival display and incisal plane inclination. Angle Orthod. 2005 Sep;75(5):778-84.

Gillen RJ, Schwartz RS, Hilton TJ, Evans DB. An analysis of selected normative tooth proportions. Int J Prosthodont. 1994 Sep-Oct;7(5):410-7.

Gul-e-Erum, Fida M. Changes in smile parameters as perceived by orthodontists, dentists, artists, and laypeople. World J Orthod. 2008 Summer;9(2):132-40.

Hulsey CM. An esthetic evaluation of lip-teeth relationships present in the smile. Am J Orthod. 1970 Feb;57(2):132-44. 
Kokich VG. Esthetics: the orthodontic-periodontic restorative connection. Semin Orthod. 1996 Mar;2(1):21-30.

Kokich VG, Spear FM. Guidelines for managing the orthodontic-restorative patient. Semin Orthod. 1997 Mar;3(1):3-20.

Kokich VO Jr, Kiyak HA, Shapiro PA. Comparing the perception of dentists and lay people to altered dental esthetics. J Esthet Dent. 1999;11(6):311-24.

Kokich VO, Kokich VG, Kiyak HA. Perceptions of dental professionals and laypersons to altered dental esthetics: asymmetric and symmetric situations. Am J Orthod Dentofacial Orthop. 2006 Aug;130(2):141-51.

Landis JR, Koch GG. The measurement of observer agreement for categorical data. Biometrics. 1977 Mar;33(1):159-74.

Langlois JH, Kalakanis L, Rubenstein AJ, Larson A, Hallam M, Smoot M. Maxims or myths of beauty? A meta-analytic and theoretical review. Psychol Bull. 2000 May;126(3):390-423.

Levin El. Dental esthetics and the golden proportion. J Prosthet Dent. 1978 Sep;40(3):244-52.

Liébart MF, Fouque-Deruelle C, SAntini A, Dillier FL, Monnet-Corti V, Glise JM, Borghetti A. Smile line and periodontium visibility. Perio. 2004; 1(1):17-25.

Loffredo LCM, Freitas JAS, Grigolli AAG. Prevalência de fissuras orais de 1975 a 1994.Revista de Saúde Pública. 2011: 571-575.

Lombardi RE. The principles of visual perception and their clinical application to denture esthetics. J Prosthet Dent. 1973 Apr;29(4):358-82.

Lourenço Ribeiro L, Teixeira Das Neves L, Costa B, Ribeiro Gomide M. Dental anomalies of the permanent lateral incisors and prevalence of hypodontia outside the cleft area in complete unilateral cleft lip and palate. Cleft Palate Craniofac J. 2003 Mar;40(2):172-5. 
Machado AW. 10 commandments of smile esthetics. Dental Press Journal of Orthodontics. 2014; 19(4):136-157. https://dx.doi.org/10.1590/2176-9451.19.4.136157.sar

Machado AW, Moon W, Gandini LG Jr. Influence of maxillary incisor edge asymmetries on the perception of smile esthetics among orthodontists and laypersons. Am J Orthod Dentofacial Orthop. 2013 May;143(5):658-64. doi: 10.1016/j.ajodo.2013.02.013.

Magne P, Gallucci G, Belser U. Anatomic crown width/length ratios of unworn and worn maxillary teeth in white subjects. J Prosthet Dent. 2003;89(5):453-461. doi:10.1016/s0022-3913(03)00125-2

Mars M, Plint DA, Houston WJ, Bergland O, Semb G. The Goslon Yardstick: a new system of assessing dental arch relationships in children with unilateral clefts of the lip and palate. Cleft Palate J. 1987 Oct;24(4):314-22.

Matthews TG. The anatomy of a smile. J Prosthet Dent. 1978 Feb;39(2):128-34.

Mattos CM, Santana RB. A quantitative evaluation of the spatial displacement of the gingival zenith in the maxillary anterior dentition. J Periodontol. 2008 Oct;79(10):1880-5. doi: 10.1902/jop.2008.080053 .

Morley J, Eubank J. Macroesthetic elements of smile design. J Am Dent Assoc. 2001 Jan;132(1):39-45.

Ødegaard J, Meling E, Meling T. An evaluation of the torsional moments developed in orthodontic applications. An in vitro study Am J Orthod Dentofacial Orthop. 1994;105(4):392-400. doi:10.1016/s0889-5406(94)70134-2.

Orce-Romero A, Iglesias-Linares A, Cantillo-Galindo M, Yañez-Vico RM, MendozaMendoza A, Solano-Reina E. Do the smiles of the world's most influential individuals have common parameters? J Oral Rehabil. 2013 Mar;40(3):159-70. doi: 10.1111/joor.12027.

Ozawa TO. Avaliação dos efeitos da queiloplastia e palatoplastia primária sobre o crescimento dos arcos dentários de crianças com fissura transforame incisivo 
unilateral aos 5-6 anos de idade. 2001. 168 f. Tese (doutorado) - Universidade Estadual Paulista, Faculdade de Odontologia de Araraquara, 2001. Disponível em: <http://hdl.handle.net/11449/104533>.

Ozawa TO, Shaw WC, Katsaros C, Kuijpers-Jagtman AM, Hagberg C, Rønning E, Semb G. A new yardstick for rating dental arch relationship in patients with complete bilateral cleft lip and palate. Cleft Palate Craniofac J. 2011 Mar;48(2):167-72. doi: 10.1597/09-122.

Preston JD. The golden proportion revisited. J Esthet Dent. 1993;5(6):247-51.

Proffit WR, Sarver DM, Ackerman JL. Diagnóstico ortodôntico: desenvolvimento de uma lista de problemas. In: Proffit WR, Fields Jr HW, Sarver DM. Ortodontia Contemporânea, 4th Ed. Elsevier, 2007. cap. 7, p. 155-216.

Rodrigues Cde D, Magnani R, Machado MS, Oliveira OB. The perception of smile attractiveness. Angle Orthod. 2009 Jul;79(4):634-9. doi: 10.2319/030508-131.1.

Rosenstiel SF, Ward DH, Rashid RG. Dentists' preferences of anterior tooth proportion--a web-based study. J Prosthodont. 2000 Sep;9(3):123-36.

Sarver DM. Principles of cosmetic dentistry in orthodontics: Part 1. Shape and proportionality of anterior teeth. Am J Orthod Dentofacial Orthop. 2004 Dec;126(6):749-53.

Sarver DM. The importance of incisor positioning in the esthetic smile: the smile arc. Am J Orthod Dentofacial Orthop. 2001 Aug;120(2):98-111.

Semb G. A Study of Facial Growth in Patients with Bilateral Cleft Lip and Palate Treated by the Oslo CLP Team. The Cleft Palate-Craniofacial Journal. 1991;28(1):22-39. doi:10.1597/1545-1569(1991)028<0022:asofgi>2.3.co;2.

Sharma PK, Sharma P. Dental smile esthetics: The assessment and creation of the ideal smile. Seminars in Orthodontics. 2012 September;18(3):193-201.

Silva-Filho OG, Ozawa TO, Borges HC. A influência da queiloplastia realizada em tempo único e em dois tempos cirúrgicos no padrão oclusal de crianças com fissura 
bilateral completa de lábio e palato. Revista Dental Press de Ortodontia e Ortopedia Facial. 2007;12(2):24-37.

Silva Filho, O. G., Teles, S. G., Ozawa, T. O., \& Filho, L. C. Secondary bone graft and eruption of the permanent canine in patients with alveolar clefts: literature review and case report. Angle Orthod. 2000; 70(2), 174-178.

Snow SR. Esthetic smile analysis of maxillary anterior tooth width: the golden percentage. J Esthet Dent. 1999;11(4):177-84.

Sterrett JD, Oliver T, Robinson F, Fortson W, Knaak B, Russell CM. Width/length ratios of normal clinical crowns of the maxillary anterior dentition in man. $\mathrm{J}$ Clin Periodontol. 1999 Mar;26(3):153-7.

Suzuki L, Machado AW, Bittencourt MAV. An evaluation of the influence of gingival display level in the smile esthetics. Dental Press J Orthod. 2011;16(5):37-39.

Tarnow DP, Magner AW, Fletcher P. The effect of the distance from the contact point to the crest of bone on the presence or absence of the interproximal dental papilla. $J$ Periodontol. 1992 Dec;63(12):995-6.

Thomas PT, Turner SR, Rumsey N, Dowell T, Sandy JR. Satisfaction with facial appearance among subjects affected by a cleft. Cleft Palate Craniofac J. 1997 May;34(3):226-31.

Tjan AH, Miller GD, The JG. Some esthetic factors in a smile. J Prosthet Dent. 1984 Jan;51(1):24-8.

Trindade IEK; Silva-Filho OG. Fissuras Labiopalatinas: uma Abordagem Interdisciplinar. Santos, 2007

Trindade IK, Mazzottini R, Silva Filho OG, Trindade IE, Deboni MC. Long-term radiographic assessment of secondary alveolar bone grafting outcomes in patients with alveolar clefts. Oral Surg Oral Med Oral Pathol Oral Radiol Endod. 2005 Sep;100(3):271-7. 
Van der Geld P, Oosterveld P, Van Heck G, Kuijpers-Jagtman AM. Smile attractiveness. Self-perception and influence on personality. Angle Orthod. 2007 Sep;77(5):759-65.

Ward $\mathrm{DH}$. Proportional smile design using the recurring esthetic dental (red) proportion. Dent Clin North Am. 2001 Jan;45(1):143-54.

Ward DH. Proportional Smile Design: Using the Recurring Esthetic Dental Proportion to Correlate the Widths and Lengths of the Maxillary Anterior Teeth with the Size of the Face. Dent Clin North Am. 2015 Jul;59(3):623-38. doi: 10.1016/j.cden.2015.03.006.

Wolfart S, Thormann H, Freitag S, Kern M. Assessment of dental appearance following changes in incisor proportions. Eur J Oral Sci. 2005 Apr;113(2):159-65.

Woodworth D, Sinclair P, Alexander R. Bilateral congenital absence of maxillary lateral incisors: A craniofacial and dental cast analysis. Am J Orthod. 1985;87(4):280293. doi:10.1016/0002-9416(85)90003-x.

Yang S, Guo Y, Yang X, Zhang F4, Wang J, Qiu J, Li J. Effect of mesiodistal angulation of the maxillary central incisors on esthetic perceptions of the smile in the frontal view. Am J Orthod Dentofacial Orthop. 2015 Sep;148(3):396-404. doi: 10.1016/j.ajodo.2015.03.021.

Zachrisson B, Rosa M, Toreskog S. Congenitally missing maxillary lateral incisors: Canine substitution. Am J Orthod Dentofacial Orthop. 2011;139(4):434-444. doi:10.1016/j.ajodo.2011.02.003.

Ziahosseini P, Hussain F, Millar BJ. Management of gingival black triangles. Br Dent J. 2014 Nov;217(10):559-63. doi: 10.1038/sj.bdj.2014.1004.

Zhou W, Li W, Lin J, Liu D, Xie X, Zhang Z. Tooth lengths of the permanent upper incisors in patients with cleft lip and palate determined with cone beam computed tomography. Cleft Palate Craniofac J. 2013 Jan;50(1):88-95. doi: 10.1597/11-182. 

Anexas 

Anexos

Anexo 1: Análise descritiva dos pacientes pertencentes ao grupo SF e FU.

\begin{tabular}{c|c|c|c|c|c|c|c|c|c|c}
\hline Sujeito & $\begin{array}{c}\text { Idade } \\
\text { (anos) }\end{array}$ & Gênero & Raça & $\begin{array}{c}\text { Cirurgia } \\
\text { ortognática } \\
\text { (Avanço da } \\
\text { Maxila) }\end{array}$ & $\begin{array}{c}\text { Reanatomização } \\
\text { por acréscimo }\end{array}$ & $\begin{array}{c}\text { Reanatomização } \\
\text { por desgaste }\end{array}$ & Agenesia & $\begin{array}{c}\text { Alteração } \\
\text { dentária }\end{array}$ & $\begin{array}{c}\text { Lado da } \\
\text { fissura }\end{array}$ & $\begin{array}{c}\text { Recessão } \\
\text { gengival }\end{array}$ \\
\hline 1 & 26 & $\mathrm{M}$ & $\mathrm{B}$ & $\mathrm{P}$ & $\mathrm{A}$ & $\mathrm{P}\left(13^{*}\right)$ & 12 & $\mathrm{~A}$ & $\mathrm{D}$ & $\mathrm{P}\left(14^{*}\right)$ \\
\hline 2 & 23 & $\mathrm{M}$ & $\mathrm{B}$ & $\mathrm{A}$ & $\mathrm{A}$ & $\mathrm{P}\left(13^{*}\right)$ & 12 & $\mathrm{~A}$ & $\mathrm{D}$ & $\mathrm{P}\left(13^{*}\right)$ \\
\hline 3 & 22 & $\mathrm{M}$ & $\mathrm{B}$ & $\mathrm{A}$ & $\mathrm{A}$ & $\mathrm{P}\left(13^{*}\right)$ & 12 & $\mathrm{~A}$ & $\mathrm{D}$ & $\mathrm{A}$ \\
\hline 4 & 21 & $\mathrm{M}$ & $\mathrm{B}$ & $\mathrm{P}$ & $\mathrm{A}$ & $\mathrm{P}\left(13^{*}\right)$ & 12 & $\mathrm{~A}$ & $\mathrm{D}$ & $\mathrm{P}\left(13^{*}\right)$ \\
\hline 5 & 18 & $\mathrm{~F}$ & $\mathrm{~B}$ & $\mathrm{~A}$ & $\mathrm{~A}$ & $\mathrm{P}\left(13^{*}\right)$ & 12 & $\mathrm{~A}$ & $\mathrm{D}$ & $\mathrm{A}$ \\
\hline 6 & 16 & $\mathrm{M}$ & $\mathrm{B}$ & $\mathrm{A}$ & $\mathrm{A}$ & $\mathrm{A}$ & 12 & $\mathrm{~A}$ & $\mathrm{D}$ & $\mathrm{A}$ \\
\hline 7 & 15 & $\mathrm{M}$ & $\mathrm{B}$ & $\mathrm{A}$ & $\mathrm{A}$ & $\mathrm{P}\left(13^{*}\right)$ & 12 & $\mathrm{~A}$ & $\mathrm{D}$ & $\mathrm{A}$ \\
\hline 8 & 24 & $\mathrm{M}$ & $\mathrm{B}$ & $\mathrm{A}$ & $\mathrm{A}$ & $\mathrm{P}\left(13^{*}\right)$ & 12 & $\mathrm{~A}$ & $\mathrm{D}$ & $\mathrm{P}\left(14^{*}, 13^{*}, 11\right)$ \\
\hline 9 & 26 & $\mathrm{M}$ & $\mathrm{B}$ & $\mathrm{P}$ & $\mathrm{A}$ & $\mathrm{P}\left(13^{*}\right)$ & 12 & $\mathrm{~A}$ & $\mathrm{D}$ & $\mathrm{P}(11)$ \\
\hline 10 & 25 & $\mathrm{M}$ & $\mathrm{B}$ & $\mathrm{A}$ & $\mathrm{A}$ & $\mathrm{A}$ & 12 & $\mathrm{~A}$ & $\mathrm{D}$ & $\mathrm{A}$ \\
\hline 11 & 21 & $\mathrm{~F}$ & $\mathrm{~B}$ & $\mathrm{~A}$ & $\mathrm{P}$ & $\mathrm{P}(22)$ & 12 & $\mathrm{~A}$ & $\mathrm{D}$ & $\mathrm{A}$ \\
\hline 12 & 22 & $\mathrm{M}$ & $\mathrm{B}$ & $\mathrm{A}$ & $\mathrm{A}$ & $\mathrm{P}\left(13^{*}\right)$ & 12 & $\mathrm{~A}$ & $\mathrm{D}$ & $\mathrm{A}$ \\
\hline 13 & 22 & $\mathrm{M}$ & $\mathrm{B}$ & $\mathrm{P}$ & $\mathrm{A}$ & $\mathrm{P}\left(13^{*}\right)$ & 12 & $\mathrm{~A}$ & $\mathrm{D}$ & $\mathrm{A}$ \\
\hline 14 & 24 & $\mathrm{~F}$ & $\mathrm{~B}$ & $\mathrm{~A}$ & $\mathrm{P}$ & $\mathrm{P}\left(13^{*}\right)$ & 12 & $\mathrm{~A}$ & $\mathrm{D}$ & $\mathrm{A}$ \\
\hline 15 & 20 & $\mathrm{M}$ & $\mathrm{B}$ & $\mathrm{A}$ & $\mathrm{A}$ & $\mathrm{P}\left(13^{*}\right)$ & 12 & $\mathrm{~A}$ & $\mathrm{D}$ & $\mathrm{A}$ \\
\hline 16 & 21 & $\mathrm{M}$ & $\mathrm{B}$ & $\mathrm{A}$ & $\mathrm{A}$ & $\mathrm{A}$ & 12 & $\mathrm{~A}$ & $\mathrm{D}$ & $\mathrm{P}(11)$ \\
\hline 17 & 28 & $\mathrm{~F}$ & $\mathrm{~B}$ & $\mathrm{~A}$ & $\mathrm{~A}$ & $\mathrm{~A}$ & 12 & $\mathrm{~A}$ & $\mathrm{D}$ & $\mathrm{A}$ \\
\hline 18 & 25 & $\mathrm{M}$ & $\mathrm{B}$ & $\mathrm{P}$ & $\mathrm{A}$ & $\mathrm{P}\left(13^{*}\right)$ & 12 & $\mathrm{~A}$ & $\mathrm{D}$ & $\mathrm{A}$ \\
\hline 19 & 25 & $\mathrm{M}$ & $\mathrm{B}$ & $\mathrm{P}$ & $\mathrm{A}$ & $\mathrm{P}\left(13^{*}\right)$ & 12 & $\mathrm{~A}$ & $\mathrm{D}$ & $\mathrm{A}$ \\
\hline 20 & 21 & $\mathrm{M}$ & $\mathrm{B}$ & $\mathrm{P}$ & $\mathrm{P}$ & $\mathrm{P}\left(13^{*}\right)$ & 12 & $\mathrm{~A}$ & $\mathrm{D}$ & $\mathrm{A}$ \\
\hline 21 & 16 & $\mathrm{~F}$ & $\mathrm{~B}$ & $\mathrm{~A}$ & $\mathrm{~A}$ & $\mathrm{P}\left(13^{*}\right)$ & 12 & $\mathrm{~A}$ & $\mathrm{D}$ & $\mathrm{A}$ \\
\hline 22 & 19 & $\mathrm{M}$ & $\mathrm{B}$ & $\mathrm{A}$ & $\mathrm{A}$ & $\mathrm{P}\left(13^{*}\right)$ & 12 & $22-\mathrm{coN} I \mathrm{CO}$ & $\mathrm{D}$ & $\mathrm{A}$ \\
\hline 23 & 22 & $\mathrm{M}$ & $\mathrm{B}$ & $\mathrm{A}$ & $\mathrm{A}$ & $\mathrm{P}\left(13^{*}\right)$ & 12 & $\mathrm{~A}$ & $\mathrm{D}$ & $\mathrm{P}(11)$ \\
\hline
\end{tabular}




\begin{tabular}{|c|c|c|c|c|c|c|c|c|c|c|}
\hline 24 & 19 & $\mathrm{~F}$ & B & $\mathrm{P}$ & A & A & 22 & A & $E$ & $\mathrm{P}(21)$ \\
\hline 25 & 19 & $\mathrm{~F}$ & $B$ & $P$ & A & $\mathrm{P}\left(23^{*}\right)$ & 22 & $A$ & $E$ & $A$ \\
\hline 26 & 20 & $\mathrm{~F}$ & $\mathrm{~B}$ & A & A & $\mathrm{P}\left(23^{*}\right)$ & 22 & $A$ & $\mathrm{E}$ & $\mathrm{P}(21$ \\
\hline 27 & 17 & $\mathrm{M}$ & $B$ & A & A & $\mathrm{P}\left(23^{*}\right)$ & 22 & $A$ & $E$ & $\mathrm{~A}$ \\
\hline 28 & 17 & $\mathrm{M}$ & $B$ & A & A & $\mathrm{P}\left(23^{*}\right)$ & 22 & $A$ & $E$ & $\mathrm{P}(21)$ \\
\hline 29 & 19 & $M$ & $B$ & A & A & A & 22 & $A$ & $E$ & $\mathrm{P}(21)$ \\
\hline 30 & 22 & M & B & A & $\mathrm{P}$ & $\mathrm{P}\left(23^{*}\right)$ & 22 & A & $\mathrm{E}$ & A \\
\hline 31 & 19 & M & B & A & A & A & 22 & A & $\mathrm{E}$ & A \\
\hline 32 & 25 & $M$ & $B$ & A & A & $\mathrm{P}\left(23^{*}\right)$ & 22 & $A$ & $E$ & $\mathrm{P}\left(21,23^{*}, 24^{*}\right)$ \\
\hline 33 & 18 & $M$ & $B$ & A & $P$ & $\mathrm{P}(23 *)$ & 22 & $A$ & $E$ & $\mathrm{P}(21)$ \\
\hline 34 & 21 & $\mathrm{~F}$ & $B$ & A & A & $\mathrm{P}\left(23^{*}\right)$ & 22 & $A$ & $E$ & $\mathrm{P}(21)$ \\
\hline 35 & 20 & $\mathrm{~F}$ & $B$ & A & A & A & 22 & A & $E$ & A \\
\hline 36 & 17 & $\mathrm{~F}$ & $B$ & A & A & $\mathrm{P}\left(23^{*}\right)$ & 22 & A & $E$ & A \\
\hline 37 & 18 & $\mathrm{~F}$ & $B$ & $P$ & A & A & 22 & A & $E$ & A \\
\hline 38 & 26 & $M$ & $B$ & $P$ & $P$ & $\mathrm{P}\left(23^{*}\right)$ & 22 & A & $E$ & $\mathrm{P}\left(21,23^{*}\right)$ \\
\hline 39 & 20 & $\mathrm{~F}$ & $B$ & A & A & $\mathrm{P}\left(23^{*}\right)$ & 22 & A & $E$ & A \\
\hline 40 & 21 & $\mathrm{~F}$ & $B$ & A & A & A & 22 & A & $E$ & A \\
\hline 41 & 18 & $\mathrm{~F}$ & $B$ & A & A & $\mathrm{P}\left(23^{*}\right)$ & 12 & A & $E$ & $\mathrm{P}\left(23^{*}\right)$ \\
\hline 42 & 18 & $\mathrm{~F}$ & $B$ & $A$ & $A$ & $\mathrm{P}\left(23^{*}\right)$ & 22 & $A$ & $E$ & $P(21)$ \\
\hline 43 & 18 & $\mathrm{~F}$ & $\mathrm{~B}$ & A & A & $\mathrm{P}\left(23^{*}\right)$ & 22 & A & $E$ & $\mathrm{P}(21)$ \\
\hline 44 & 19 & $M$ & $\mathrm{~B}$ & A & A & A & 22 & A & $\mathrm{E}$ & $\mathrm{A}$ \\
\hline 45 & 19 & $\mathrm{M}$ & $B$ & A & $\mathrm{P}$ & $\mathrm{P}\left(23^{*}\right)$ & 22 & $A$ & $E$ & $P(21)$ \\
\hline 46 & 20 & $M$ & $B$ & $A$ & $\mathrm{P}$ & $\mathrm{P}(23 *)$ & 22 & $A$ & $E$ & $\mathrm{P}(21)$ \\
\hline 47 & 26 & $M$ & $B$ & $\mathrm{P}$ & $\mathrm{P}$ & $\mathrm{P}\left(23^{*}\right)$ & 22 & $A$ & $E$ & $P(21)$ \\
\hline 48 & 17 & $M$ & $B$ & $A$ & $A$ & $\mathrm{~A}$ & 22 & $A$ & $E$ & $A$ \\
\hline 49 & 22 & $\mathrm{~F}$ & $\mathrm{~B}$ & A & A & $\mathrm{P}(23 *)$ & 22 & $\mathrm{~A}$ & $\mathrm{E}$ & $\mathrm{P}(21)$ \\
\hline 50 & 23 & $M$ & $\mathrm{~B}$ & $A$ & $\mathrm{P}$ & $\mathrm{P}\left(23^{*}\right)$ & 22 & $\mathrm{~A}$ & $E$ & $\mathrm{P}(13,21$ \\
\hline 51 & 31 & $\mathrm{~F}$ & $\mathrm{~B}$ & $\mathrm{P}$ & $A$ & $\mathrm{P}\left(23^{*}\right)$ & 22 & $A$ & $E$ & $P(21)$ \\
\hline 52 & 24 & $\mathrm{~F}$ & B & $P$ & $P$ & $P(23 *)$ & 22 & $A$ & $E$ & $A$ \\
\hline
\end{tabular}


Anexor

\begin{tabular}{c|c|c|c|c|c|c|c|c|c|c}
\hline 53 & 24 & $\mathrm{M}$ & $\mathrm{B}$ & $\mathrm{P}$ & $\mathrm{A}$ & $\mathrm{P}\left(23^{*}\right)$ & 22 & $\mathrm{~A}$ & $\mathrm{E}$ & $\mathrm{P}(21)$ \\
\hline 54 & 20 & $\mathrm{M}$ & $\mathrm{B}$ & $\mathrm{A}$ & $\mathrm{A}$ & $\mathrm{A}$ & 22 & $\mathrm{~A}$ & $\mathrm{E}$ & $\mathrm{A}$ \\
\hline 55 & 24 & $\mathrm{M}$ & $\mathrm{N}$ & $\mathrm{P}$ & $\mathrm{A}$ & $\mathrm{P}\left(23^{*}\right)$ & 22 & $\mathrm{~A}$ & $\mathrm{E}$ & $\mathrm{P}(21)$ \\
\hline 56 & 19 & $\mathrm{~F}$ & $\mathrm{~B}$ & $\mathrm{~A}$ & $\mathrm{~A}$ & $\mathrm{P}\left(11,21,23^{*}\right)$ & 22 & $\mathrm{~A}$ & $\mathrm{E}$ & $\mathrm{A}$ \\
\hline 57 & 23 & $\mathrm{~F}$ & $\mathrm{~B}$ & $\mathrm{~A}$ & $\mathrm{~A}$ & $\mathrm{~A}$ & 22 & $\mathrm{~A}$ & $\mathrm{E}$ & $\mathrm{A}$ \\
\hline 58 & 22 & $\mathrm{M}$ & $\mathrm{B}$ & $\mathrm{P}$ & $\mathrm{P}$ & $\mathrm{P}\left(23^{*}\right)$ & 22 & $\mathrm{~A}$ & $\mathrm{E}$ & $\mathrm{P}\left(21,23^{*}\right)$ \\
\hline 59 & 24 & $\mathrm{M}$ & $\mathrm{B}$ & $\mathrm{P}$ & $\mathrm{A}$ & $\mathrm{A}$ & 22 & $\mathrm{~A}$ & $\mathrm{E}$ & $\mathrm{P}(13,12,11,12,13)$ \\
\hline
\end{tabular}

Legenda: M: masculino; F: feminino; B: branco; N: negro; A: ausente; P: presente; D: direito; E: esquerdo; *canino na posição do incisivo lateral ou $1^{\circ}$ pré-molar na posição do canino; ${ }^{* *} 1^{\circ}$ pré-molar na posição do incisivo lateral. 
Anexo 2: Análise descritiva dos pacientes pertencentes ao grupo FB.

\begin{tabular}{|c|c|c|c|c|c|c|c|c|c|}
\hline Sujeito & $\begin{array}{l}\text { Idade } \\
\text { (anos) }\end{array}$ & Gênero & Raça & $\begin{array}{c}\text { Cirurgia } \\
\text { ortognática } \\
\text { (Avanço da } \\
\text { Maxila) }\end{array}$ & $\begin{array}{l}\text { Reanatomização } \\
\text { por acréscimo }\end{array}$ & $\begin{array}{c}\text { Reanatomização } \\
\text { por desgaste }\end{array}$ & Agenesia & $\begin{array}{l}\text { Alteração } \\
\text { dentária }\end{array}$ & Recessão gengival \\
\hline 1 & 35 & $M$ & B & $\mathrm{P}$ & $A$ & $P\left(13^{*}, 23^{*}\right)$ & $P(12,22)$ & $A$ & $P\left(11,21,23^{*}\right)$ \\
\hline 2 & 29 & $M$ & B & $\mathrm{P}$ & A & $\mathrm{P}\left(13^{*}, 23^{*}, 14^{*}\right)$ & $P(12,22)$ & A & $\begin{array}{c}\mathrm{P} \\
\left(14^{*}, 13^{*}, 11,21,23^{*}, 24^{*}\right)\end{array}$ \\
\hline 3 & 27 & $M$ & B & $P$ & $P\left(23^{*}\right)$ & $\mathrm{P}\left(13^{*}, 23^{*}, 14^{*}\right)$ & $P(22)$ & $A$ & $P\left(13,11,23^{*}, 24^{*}\right)$ \\
\hline 4 & 30 & $M$ & B & $A$ & $P\left(13^{*}, 11,21,23^{*}\right)$ & $P\left(13^{*}, 23^{*}\right)$ & $P(12,22)$ & $A$ & $P\left(13^{*}, 23^{*}\right)$ \\
\hline 5 & 25 & $M$ & B & $P$ & $P(12,22)$ & $A$ & $A$ & $A$ & $P(11,21)$ \\
\hline 6 & 26 & $M$ & B & $A$ & $P\left(13^{*}, 23^{*}\right)$ & $P\left(13^{*}, 23^{*}\right)$ & $P(12,22)$ & $A$ & $A$ \\
\hline 7 & 29 & $\mathrm{M}$ & B & $P$ & A & $\mathrm{P}\left(13^{*}, 23^{*}\right)$ & $P(12,22)$ & A & $P(11,21)$ \\
\hline 8 & 30 & $M$ & B & $P$ & $A$ & $A$ & $P(12,22)$ & $A$ & $P(11,21)$ \\
\hline 9 & 26 & $\mathrm{~F}$ & $B$ & $P$ & $\mathrm{P}\left(13^{*}, 23^{*}\right)$ & $\mathrm{P}\left(13^{*}, 23^{*}\right)$ & $P(12,22)$ & $A$ & $A$ \\
\hline 10 & 24 & $\mathrm{~F}$ & B & $P$ & A & A & A & $A$ & $A$ \\
\hline 11 & 25 & $\mathrm{~F}$ & $\mathrm{~B}$ & $\mathrm{P}$ & A & $\mathrm{P}\left(13^{*} ; 24^{* *}\right)$ & $\mathrm{P}(12,22,23)$ & A & A \\
\hline 12 & 26 & $M$ & B & $P$ & $P\left(23^{*}\right)$ & $P\left(13^{*}, 23^{*}\right)$ & $P(12,22)$ & $A$ & $P\left(13^{*}, 23^{*}\right)$ \\
\hline 13 & 25 & $\mathrm{M}$ & B & $P$ & A & $\mathrm{P}\left(13^{*}, 23^{*}\right)$ & $P(12,22)$ & A & $P\left(13^{*}\right)$ \\
\hline 14 & 25 & $\mathrm{~F}$ & $\mathrm{~B}$ & A & $P(22)$ & $P\left(13^{*}\right)$ & $P(12)$ & A & A \\
\hline 15 & 25 & $M$ & B & $A$ & $A$ & $P\left(13^{*}, 23^{*}\right)$ & $P(12,22)$ & $A$ & $P(11)$ \\
\hline 16 & 24 & $M$ & B & $\mathrm{P}$ & A & $\mathrm{P}\left(13^{*}, 23^{*}\right)$ & $P(12,22)$ & A & $\mathrm{P}\left(23^{*}\right)$ \\
\hline 17 & 27 & $\mathrm{M}$ & $B$ & $\mathrm{P}$ & $\mathrm{P}\left(23^{*}\right)$ & $\mathrm{P}\left(23^{*}\right)$ & $\mathrm{P}(22)$ & A & $\mathrm{P}\left(21,24^{*}\right)$ \\
\hline 18 & 23 & $M$ & B & $A$ & $A$ & $P\left(13^{*}, 23^{*}\right)$ & $P(12,22)$ & $A$ & $P(21)$ \\
\hline 19 & 25 & $\mathrm{M}$ & $\mathrm{B}$ & $\mathrm{P}$ & $\mathrm{P}\left(13^{*}, 23^{*}\right)$ & $\mathrm{P}\left(13^{*}, 23^{*}\right)$ & $P(12,22)$ & $A$ & $P(21)$ \\
\hline 20 & 26 & $M$ & $\mathrm{~N}$ & $P$ & $P(21)$ & $A$ & $P(12,22)$ & $P(21)$ & $A$ \\
\hline
\end{tabular}




\begin{tabular}{c|c|c|c|c|c|c|c|c|c}
\hline 21 & 22 & $\mathrm{M}$ & $\mathrm{B}$ & $\mathrm{P}$ & $\mathrm{P}\left(23^{*}\right)$ & $\mathrm{P}\left(13^{*}, 23^{*}\right)$ & $\mathrm{P}(12,22)$ & $\mathrm{A}$ & $\mathrm{P}\left(23^{*}\right)$ \\
\hline 22 & 27 & $\mathrm{M}$ & $\mathrm{B}$ & $\mathrm{P}$ & $\mathrm{A}$ & $\mathrm{P}\left(13^{*}, 23^{*}\right)$ & $\mathrm{P}(12,22)$ & $\mathrm{A}$ & $\mathrm{P}\left(14^{*}, 11,21,23^{*}, 24^{*}\right)$ \\
\hline 23 & 24 & $\mathrm{~F}$ & $\mathrm{~B}$ & $\mathrm{~A}$ & $\mathrm{P}\left(13^{*}, 22\right)$ & $\mathrm{P}\left(13^{*}\right)$ & $\mathrm{P}(12)$ & $\mathrm{A}$ & $\mathrm{P}\left(23^{*}\right)$ \\
\hline 24 & 22 & $\mathrm{~F}$ & $\mathrm{~B}$ & $\mathrm{P}$ & $\mathrm{P}\left(13^{*}, 23^{*}\right)$ & $\mathrm{P}\left(13^{*}, 23^{*}\right)$ & $\mathrm{P}(12,22)$ & $\mathrm{A}$ & $\mathrm{P}(21)$ \\
\hline 25 & 24 & $\mathrm{M}$ & $\mathrm{B}$ & $\mathrm{P}$ & $\mathrm{A}$ & $\mathrm{P}\left(13^{*}, 23^{*}\right)$ & $\mathrm{P}(12,22)$ & $\mathrm{A}$ & $\mathrm{P}\left(23^{*}\right)$ \\
\hline 26 & 21 & $\mathrm{M}$ & $\mathrm{B}$ & $\mathrm{A}$ & $\mathrm{P}\left(13^{*}, 23^{*}\right)$ & $\mathrm{P}\left(13^{*}, 23^{*}\right)$ & $\mathrm{P}(12,22)$ & $\mathrm{A}$ & $\mathrm{P}\left(14^{*}\right)$ \\
\hline 27 & 24 & $\mathrm{M}$ & $\mathrm{B}$ & $\mathrm{A}$ & $\mathrm{A}$ & $\mathrm{A}$ & $\mathrm{P}(12,22)$ & $\mathrm{A}$ & $\mathrm{P}\left(13^{*}, 23^{*}\right)$ \\
\hline 28 & 23 & $\mathrm{M}$ & $\mathrm{N}$ & $\mathrm{P}$ & $\mathrm{A}$ & $\mathrm{P}\left(13^{*}, 23^{*}\right)$ & $\mathrm{P}(12,22)$ & $\mathrm{A}$ & $\mathrm{P}(21)$ \\
\hline 29 & 26 & $\mathrm{M}$ & $\mathrm{B}$ & $\mathrm{A}$ & $\mathrm{A}$ & $\mathrm{P}\left(13^{*}\right)$ & $\mathrm{P}(12)$ & $\mathrm{A}$ & $\mathrm{P}(22)$ \\
\hline 30 & 20 & $\mathrm{M}$ & $\mathrm{B}$ & $\mathrm{A}$ & $\mathrm{P}\left(13^{*}, 11,21,23^{*}\right)$ & $\mathrm{P}\left(13^{*}, 23^{*}\right)$ & $\mathrm{P}(12,22)$ & $\mathrm{A}$ & $\mathrm{P}\left(14^{*}\right)$ \\
\hline 31 & 23 & $\mathrm{~F}$ & $\mathrm{~B}$ & $\mathrm{P}$ & $\mathrm{A}$ & $\mathrm{P}\left(13^{*}, 23^{*}\right)$ & $\mathrm{P}(12,22)$ & $\mathrm{P}(21)$ & $\mathrm{P}\left(13^{*}, 11,21\right)$ \\
\hline 32 & 25 & $\mathrm{M}$ & $\mathrm{B}$ & $\mathrm{A}$ & $\mathrm{A}$ & $\mathrm{P}\left(14^{*}, 13^{*}, 23^{*}, 24^{*}\right)$ & $\mathrm{P}(12,22)$ & $\mathrm{A}$ & $\mathrm{P}\left(13^{*}, 23^{*}\right)$ \\
\hline 33 & 21 & $\mathrm{~F}$ & $\mathrm{~B}$ & $\mathrm{P}$ & $\mathrm{P}\left(12,23^{*}\right)$ & $\mathrm{P}\left(23^{*}\right)$ & $\mathrm{P}(22)$ & $\mathrm{A}$ & $\mathrm{A}$ \\
\hline 34 & 17 & $\mathrm{M}$ & $\mathrm{B}$ & $\mathrm{A}$ & $\mathrm{A}$ & $\mathrm{A}$ & $\mathrm{A}$ & $\mathrm{A}$ & $\mathrm{P}(12,21,22)$ \\
\hline 35 & 18 & $\mathrm{M}$ & $\mathrm{B}$ & $\mathrm{A}$ & $\mathrm{A}$ & $\mathrm{P}\left(23^{*}\right)$ & $\mathrm{P}(22)$ & $\mathrm{P}(12)$ & $\mathrm{P}(21)$ \\
\hline 36 & 20 & $\mathrm{~F}$ & $\mathrm{~B}$ & $\mathrm{P}$ & $\mathrm{P}\left(13^{*}, 11,21,23^{*}\right)$ & $\mathrm{P}\left(13^{*}, 23^{*}\right)$ & $\mathrm{P}(12,22)$ & $\mathrm{A}$ & $\mathrm{A}$ \\
\hline 37 & 20 & $\mathrm{~F}$ & $\mathrm{~B}$ & $\mathrm{~A}$ & $\mathrm{P}(12,22)$ & $\mathrm{A}$ & $\mathrm{A}$ & $\mathrm{A}$ & $\mathrm{A}$ \\
\hline 38 & 22 & $\mathrm{~F}$ & $\mathrm{~B}$ & $\mathrm{P}$ & $\mathrm{P}\left(13^{*}, 11,21,23^{*}\right)$ & $\mathrm{P}\left(13^{*}, 23^{*}\right)$ & $\mathrm{P}(12,22)$ & $\mathrm{A}$ & $\mathrm{A}$ \\
\hline 39 & 19 & $\mathrm{~F}$ & $\mathrm{~B}$ & $\mathrm{P}$ & $\mathrm{A}$ & $\mathrm{P}\left(13^{*}, 23^{*}\right)$ & $\mathrm{P}(12,22)$ & $\mathrm{A}$ & $\mathrm{A}$ \\
\hline 40 & 20 & $\mathrm{~F}$ & $\mathrm{~B}$ & $\mathrm{~A}$ & $\mathrm{P}\left(13^{*}, 11,21,23^{*}\right)$ & $\mathrm{P}\left(13^{*}, 23^{*}\right)$ & $\mathrm{A}$ & $\mathrm{A}$ & $\mathrm{A}$ \\
\hline 41 & 19 & $\mathrm{M}$ & $\mathrm{B}$ & $\mathrm{A}$ & $\mathrm{A}$ & $\mathrm{A}$ & $\mathrm{A}$ & $\mathrm{A}$ & $\mathrm{P}(13,23)$ \\
\hline
\end{tabular}

Legenda: M: masculino; F: feminino; B: branco; N: negro; A: ausente; P: presente; D: direito; E: esquerdo; *canino na posição do incisivo lateral ou $1^{\circ}$ pré-molar na posição do canino; ** $1^{\circ}$ pré-molar na posição do incisivo lateral 


\section{Anexo 3 - Carta de aprovação do CEP}

USP - HOSPITAL DE
REABILITAÇÃO DE
ANOMALIAS CRANIOFACIAIS
PARECER CONSUBSTANCIADO DO CEP

\section{DADOS DO PROJETO DE PESQUISA}

Título da Pesquisa: Avaliação da microestética dentária em pacientes com fissura transforame incisivo bilateral utilizando modelos digitais obtidos por escaneamento intraoral.

Pesquisador: DANIEL LUIS PIRES ROSA

Área Temática:

Versão: 2

CAAE: 62382916.2 .0000 .5441

Instituição Proponente: Hospital de Reabilitação de Anomalias Craniofaciais da USP

Patrocinador Principal: Financiamento Próprio

\section{DADOS DO PARECER}

Número do Parecer: 1.905.387

\section{Apresentação do Projeto:}

Trata-se de um projeto de Dissertação, de autoria de DANIEL LUIS PIRES ROSA sob orientação de Ana Lúcia Pompéia Fraga de Almeida e co-orientação de DANIELA GAMBA GARIB CARREIRA. O presente estudo trata-se de uma análise indutiva/inferencial dos dados coletados em modelos digitais referentes à microestética dentária, visando à comparação entre variáveis quantitativas de dois grupos (teste e controle). O grupo teste será formado por 77 modelos digitais, obtidos por escaneamento intraoral pós tratamento ortodôntico, de 77 indivíduos com fissura transforame incisivo bilateral (FTIB), com idades entre 16 e 25 anos e sem próteses na região antero-superior. O grupo controle definir-se-á por 51 modelos digitais, obtidos por escaneamento dos modelos de gesso, de 51 jovens adultos com 17 anos de idade, sem fissura orofacial, com oclusão normal e sem próteses na região antero-superior.No intuito de verificar a hipótese nula de não haver diferença nos aspectos microestéticos dentários de adultos jovens com FTIB após tratamento ortodôntico (grupo teste) e sem fissura com oclusão normal (grupo controle), será calculado a média e desvio-padrão das variáveis analisadas.

\section{Objetivo da Pesquisa:}

Contribuir para o enriquecimento dos componentes do sorriso e sua influência estética em

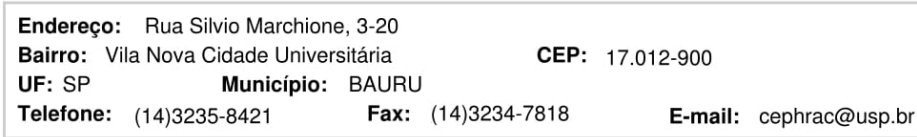




\section{USP - HOSPITAL DE
REABILITAÇÃO DE
ANOMALIAS CRANIOFACIAIS}

Continuação do Parecer: 1.905 .387

pacientes com FLP e respaldar a tomada de decisão do profissional reabilitador.

Avaliar a os aspectos microestéticos dos dentes anterosuperiores de indivíduos com fissura transforame incisivo bilateral (FTIB), após a finalização ortodôntica de adultos jovens reabilitados no Hospital de Anomalias Craniofaciais da Universidade de São Paulo (HRAC-USP). Comparar os aspectos microestéticos dentários do grupo teste com aqueles obtidos de amostra de adultos jovens sem fissura labiopalatina e com oclusão normal

\section{Avaliação dos Riscos e Benefícios:}

Riscos: Náusea e Vômito. Todos os riscos são mínimos, já que estão relacionados à predisposição individual e a possíveis contatos da ponteira intraoral com áreas estimuladoras dos referidos reflexos. A ponteira intraoral do scanner é esterilizável e o HRAC-USP dispõe de rigorosa rotina de esterilização, além de existirem diversas ponteiras à disposição. O processo de escaneamento intraoral resume-se a tomadas de centenas de fotos rearranjadas tridimensionalmente por um software, portanto não envolvendo radiação $X$ Benefícios: A reabilitação do indivíduo com FLP deve objetivar não só aspectos funcionais, mas também estéticos. Intenciona-se com isso permitir que esses indivíduos possam desenvolver-se psicossocialmente de forma mais salutar. Dessa forma, o profissional reabilitador, sem perder sua criatividade artística, deve pautar-se por princípios estéticos respaldados cientificamente. Em vista de tais argumentos, o presente estudo propõe-se a enriquecer a base cientifica que servirá de suporte para tomada de decisão do dentista reabilitador. Favorecendo, por conseguinte, a melhora do resultado estético do sorriso, ponto chave na estética facial e da interação social.

\section{Comentários e Considerações sobre a Pesquisa:}

Pesquisa bem delineada e com mérito científico.

Considerações sobre os Termos de apresentação obrigatória:

Todos os seguintes termos foram apresentados adequadamente:

Carta de encaminhamento dos pesquisadores aos CEP;

Formulário HRAC;

Folha de Rosto Plataforma Brasil;

Termo de Compromisso de Manuseio de Informações;

Termo de Permissão para uso de Registros para Fins Clentíficos;

Termo de Compromisso de Tornar Públicos os Resultados da Pesquisa e Destinação de Materiais ou Dados Coletados;

Termo de Compromisso do Pesquisador Responsável.

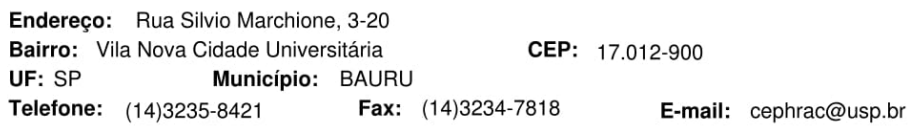




\section{USP - HOSPITAL DE \\ REABILITAÇÃO DE ANOMALIAS CRANIOFACIAIS}

Continuação do Parecer: 1.905 .387

Recomendações:

Não há

Conclusões ou Pendências e Lista de Inadequações:

Todas as irregularidades foram corrigidas, assim, sugiro aprovação do projeto.

Considerações Finais a critério do CEP:

O pesquisador deve atentar que o projeto de pesquisa aprovado por este CEP refere-se ao protocolo submetido para avaliação. Portanto, conforme a Resolução CNS 466/12, o pesquisador é responsável por "desenvolver o projeto conforme delineado", se caso houver alterações nesse projeto, este CEP deverá ser comunicado em emenda via Plataforma Brasil, para nova avaliação.

Cabe ao pesquisador notificar via Plataforma Brasil o relatório final para avaliação. Os Termos de Consentimento Livre e Esclarecidos e/ou outros Termos obrigatórios assinados pelos participantes da pesquisa deverão ser entregues ao CEP. Os relatórios semestrais devem ser notificados quando solicitados no parecer.

Este parecer foi elaborado baseado nos documentos abaixo relacionados:

\begin{tabular}{|c|c|c|c|c|}
\hline Tipo Documento & Arquivo & Postagem & Autor & Situação \\
\hline $\begin{array}{l}\text { Informações Básicas } \\
\text { do Projeto }\end{array}$ & $\begin{array}{l}\text { PB_INFORMAÇŐES_BASICAS_DO_P } \\
\text { ROJETO 828904.pdf }\end{array}$ & $\begin{array}{l}03 / 01 / 2017 \\
23: 06: 32\end{array}$ & & Aceito \\
\hline $\begin{array}{l}\text { TCLE / Termos de } \\
\text { Assentimento / } \\
\text { Justificativa de } \\
\text { Ausência }\end{array}$ & $\begin{array}{l}\text { AssentimentoLivreEsclarecido_CORRIG } \\
\text { IDO.docx }\end{array}$ & $\begin{array}{l}03 / 01 / 2017 \\
22: 53: 02\end{array}$ & $\begin{array}{l}\text { DANIEL LUIS PIRES } \\
\text { ROSA }\end{array}$ & Aceito \\
\hline $\begin{array}{l}\text { TCLE / Termos de } \\
\text { Assentimento / } \\
\text { Justificativa de } \\
\text { Ausência }\end{array}$ & TermoConsentimento_Corrigido.docx & $\begin{array}{l}03 / 01 / 2017 \\
22: 52: 35\end{array}$ & $\begin{array}{l}\text { DANIEL LUIS PIRES } \\
\text { ROSA }\end{array}$ & Aceito \\
\hline Outros & Oficio_Resposta_Assinado.pdf & $\begin{array}{c}03 / 01 / 2017 \\
22: 32: 19\end{array}$ & $\begin{array}{l}\text { DANIEL LUIS PIRES } \\
\text { ROSA }\end{array}$ & Aceito \\
\hline $\begin{array}{l}\text { Projeto Detalhado / } \\
\text { Brochura } \\
\text { Investigador }\end{array}$ & $\begin{array}{l}\text { Projeto_Pesquisa_FINALsemANEXO_C } \\
\text { ronogramaCorrigido.doc }\end{array}$ & $\begin{array}{c}03 / 01 / 2017 \\
21: 11: 47\end{array}$ & $\begin{array}{l}\text { DANIEL LUIS PIRES } \\
\text { ROSA }\end{array}$ & Aceito \\
\hline Cronograma & Cronograma_corrigido.docx & $\begin{array}{c}03 / 01 / 2017 \\
21: 07: 26\end{array}$ & $\begin{array}{l}\text { DANIEL LUIS PIRES } \\
\text { ROSA }\end{array}$ & Aceito \\
\hline Outros & Checklist_Prot_Pesq_100_2016.pdf & $\begin{array}{c}25 / 11 / 2016 \\
16: 38: 09\end{array}$ & $\begin{array}{l}\text { Rafael Mattos de } \\
\text { Deus }\end{array}$ & Aceito \\
\hline Orçamento & Orcamento.docx & $\begin{array}{c}24 / 11 / 2016 \\
15: 49: 20 \\
\end{array}$ & $\begin{array}{l}\text { DANIEL LUIS PIRES } \\
\text { ROSA }\end{array}$ & Aceito \\
\hline Outros & Daniel_Term_Comp_Tornar_Publico_ & $24 / 11 / 2016$ & DANIEL LUIS PIRES & Aceito \\
\hline
\end{tabular}

Endereço: Rua Silvio Marchione, 3-20

Bairro: Vila Nova Cidade Universitária

UF: SP Município: BAURU

CEP: $17.012-900$

Telefone: (14)3235-8421 Fax: (14)3234-7818 E-mail: cephrac@usp.br 


\section{USP - HOSPITAL DE \\ REABILITAÇÃO DE ANOMALIAS CRANIOFACIAIS}

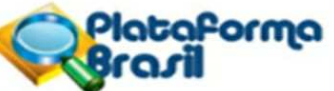

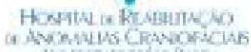

Continuação do Parecer: 1.905.387

\begin{tabular}{|c|c|c|c|c|}
\hline Outros & Dest_Mat.pdf & $15: 45: 49$ & ROSA & Aceito \\
\hline Outros & Daniel_Term_Comp_Pesq_Resp.pdf & $\begin{array}{c}24 / 11 / 2016 \\
15: 44: 59\end{array}$ & $\begin{array}{l}\text { DANIEL LUIS PIRES } \\
\text { ROSA }\end{array}$ & Aceito \\
\hline Outros & $\begin{array}{l}\text { Daniel_Term_Comp_Manuseio_Inform.p } \\
\text { df }\end{array}$ & $\begin{array}{c}24 / 11 / 2016 \\
15: 44: 06\end{array}$ & $\begin{array}{l}\text { DANIEL LUIS PIRES } \\
\text { ROSA }\end{array}$ & Aceito \\
\hline Outros & Daniel_Form_Cadastro_HRAC.pdf & $\begin{array}{c}24 / 11 / 2016 \\
15: 43: 08 \\
\end{array}$ & $\begin{array}{l}\text { DANIEL LUIS PIRES } \\
\text { ROSA }\end{array}$ & Aceito \\
\hline Outros & Daniel_Carta_Encaminham.pdf & $\begin{array}{c}24 / 11 / 2016 \\
15: 42: 10 \\
\end{array}$ & $\begin{array}{l}\text { DANIEL LUIS PIRES } \\
\text { ROSA }\end{array}$ & Aceito \\
\hline Cronograma & Cronograma.docx & $\begin{array}{c}24 / 11 / 2016 \\
15: 37: 21 \\
\end{array}$ & $\begin{array}{l}\text { DANIEL LUIS PIRES } \\
\text { ROSA }\end{array}$ & Aceito \\
\hline Folha de Rosto & Daniel_Folha_Rosto.pdf & $\begin{array}{c}24 / 11 / 2016 \\
15: 33: 15 \\
\end{array}$ & $\begin{array}{l}\text { DANIEL LUIS PIRES } \\
\text { ROSA }\end{array}$ & Aceito \\
\hline $\begin{array}{l}\text { Projeto Detalhado / } \\
\text { Brochura } \\
\text { Investigador }\end{array}$ & $\begin{array}{l}\text { Projeto_Pesquisa_FINALsemANEXO.do } \\
\text { c }\end{array}$ & $\begin{array}{c}23 / 11 / 2016 \\
15: 42: 12\end{array}$ & $\begin{array}{l}\text { DANIEL LUIS PIRES } \\
\text { ROSA }\end{array}$ & Aceito \\
\hline $\begin{array}{l}\text { TCLE / Termos de } \\
\text { Assentimento / } \\
\text { Justificativa de } \\
\text { Ausência }\end{array}$ & TermoConsentimento.docx & $\begin{array}{c}21 / 11 / 2016 \\
11: 17: 40\end{array}$ & $\begin{array}{l}\text { DANIEL LUIS PIRES } \\
\text { ROSA }\end{array}$ & Aceito \\
\hline $\begin{array}{l}\text { TCLE / Termos de } \\
\text { Assentimento / } \\
\text { Justificativa de } \\
\text { Ausência }\end{array}$ & AssentimentoLivreEsclarecido.docx & $\begin{array}{c}21 / 11 / 2016 \\
11: 13: 53\end{array}$ & $\begin{array}{l}\text { DANIEL LUIS PIRES } \\
\text { ROSA }\end{array}$ & Aceito \\
\hline
\end{tabular}

Situação do Parecer:

Aprovado

Necessita Apreciação da CONEP:

Não

BAURU, 02 de Fevereiro de 2017

Assinado por:

Renata Paciello Yamashita

(Coordenador)

Endereço: Rua Silvio Marchione, 3-20

Bairro: Vila Nova Cidade Universitária

UF: SP Município: BAURU

CEP: $\quad 17.012-900$

Telefone: (14)3235-8421 Fax: (14)3234-7818 E-mail: cephrac@usp.br 